\title{
Non anti-coagulant factors associated with filter life in continuous renal replacement therapy (CRRT): a systematic review and meta-analysis
}

\author{
Matthew Brain ${ }^{1,2,3^{*}}$, Elizabeth Winson ${ }^{3}$, Owen Roodenburg ${ }^{1,2}$ and John McNeil ${ }^{1}$
}

\begin{abstract}
Background: Optimising filter life and performance efficiency in continuous renal replacement therapy has been a focus of considerable recent research. Larger high quality studies have predominantly focussed on optimal anticoagulation however CRRT is complex and filter life is also affected by vascular access, circuit and management factors. We performed a systematic search of the literature to identify and quantify the effect of vascular access, circuit and patient factors that affect filter life and presented the results as a meta-analysis.

Methods: A systematic review and meta-analysis was performed by searching Pubmed (MEDLINE) and Ovid EMBASE libraries from inception to $29^{\text {th }}$ February 2016 for all studies with a comparator or independent variable relating to CRRT circuits and reporting filter life. Included studies documented filter life in hours with a comparator other than anti-coagulation intervention. All studies comparing anticoagulation interventions were searched for regression or hazard models pertaining to other sources of variation in filter life.
\end{abstract}

Results: Eight hundred nineteen abstracts were identified of which 364 were selected for full text analysis. 24 presented data on patient modifiers of circuit life, 14 on vascular access modifiers and 34 on circuit related factors. Risk of bias was high and findings are hypothesis generating.

Ranking of vascular access site by filter longevity favours: tunnelled semi-permanent catheters, femoral, internal jugular and subclavian last. There is inconsistency in the difference reported between femoral and jugular catheters. Amongst published literature, modality of CRRT consistently favoured continuous veno-venous haemodiafiltration (CWHD-F) with an associated $44 \%$ lower failure rate compared to $\mathrm{CWH}$. There was a trend favouring higher blood flow rates. There is insufficient data to determine advantages of haemofilter membranes.

Patient factors associated with a statistically significant worsening of filter life included mechanical ventilation, elevated SOFA or LOD score, elevations in ionized calcium, elevated platelet count, red cell transfusion, platelet factor 4 (PF-4) antibodies, and elevated fibrinogen.

Majority of studies are observational or report circuit factors in sub-analysis. Risk of bias is high and findings require targeted investigations to confirm.

(Continued on next page)

\footnotetext{
* Correspondence: matthew.brain@monash.edu

${ }^{1}$ School of Public Health and Preventive Medicine, Monash University, Melbourne, VIC, Australia

${ }^{2}$ The Alfred Intensive Care Unit, Melbourne, VIC, Australia

Full list of author information is available at the end of the article
} International License (http://creativecommons.org/licenses/by/4.0/), which permits unrestricted use, distribution, and reproduction in any medium, provided you give appropriate credit to the original author(s) and the source, provide a link to the Creative Commons license, and indicate if changes were made. The Creative Commons Public Domain Dedication waiver (http://creativecommons.org/publicdomain/zero/1.0/) applies to the data made available in this article, unless otherwise stated. 
(Continued from previous page)

Conclusion: The interaction of patient, pathology, anticoagulation, vascular access, circuit and staff factors contribute to CRRT filter life. There remains an ambiguity from published data as to which site and side should be the first choice for vascular access placement and what interaction this has with patient factors and timing. Early consideration of tunnelled semi-permanent access may provide optimal filter life if longer periods of CRRT are anticipated. There remains an absence of robust evidence outside of anti-coagulation strategies despite over 20 years of therapy delivery however trends favour CWHD-F over CWH.

Keywords: Continuous renal replacement therapy, CRRT, Vascular access, Filter life, Femoral, Jugular, Vein

\section{Background}

Continuous renal replacement therapy (CRRT) is a common intervention to maintain physiologic plasma composition when acute kidney injury (AKI) complicates critical illness. CRRT by definition relies on continuous blood flow through the extra-corporeal circuit to support controlled clearance of solutes and water balance. Failures of the extracorporeal circuit interrupt treatment delivery, increase cost and are potentially disruptive to other aspects of patient care.

Optimising filter life and performance efficiency in CRRT has been a focus of considerable recent research. Larger high quality studies have predominantly focussed on optimal anticoagulation strategies and this has formed the core of several reviews [1-6] with a recent meta-analysis $[6,7]$ favouring citrate over regional heparin to extend filter life.

Though narrative reviews exist focussing on nonanticoagulant parameters that affect filter life [1-3], no meta-analysis has ever pooled published data in this area. We performed a systematic search of the literature to identify and quantify the effect of non-anticoagulant factors and interventions that influence filter life in continuous renal replacement therapy. We have arbitrarily divided non-anticoagulant determinants of filter life into vascular access factors, circuit factors and patient factors.

Adequate vascular access allows the desired blood flow to be achieved without generating extremes of pressure between the extracorporeal circuit and the patient. Poor access results in frequent CRRT platform alarms and failure of treatment delivery or reductions in blood flow that may decrease therapy effectiveness and promote stasis with subsequent thrombosis [1-3]. Obtaining vascular access for CRRT is a frequently performed procedure. Veno-venous (VV) techniques have largely supplanted arterio-venous (AV) cannulation due to the availability and relative ease of wire-guided dual lumen catheters. However many possible combinations of vascular access catheter design, size, insertion site, inserter experience, depth of insertion and line maintenance make determining the optimal combination complex.
Patient factors such as body habitus, pathology and coagulopathy all contribute to the ease of performing CRRT and maintaining vascular access. Circuit factors include the modality of treatment with continuous veno-venous haemodialysis (CVVHD), haemofiltration $(\mathrm{CVVH})$, and haemodiafiltration (CVVHD-F) all in common usage. Variation in practice also encompasses use of pre/post dilution in CVVH and CVVHD-F, target blood and fluid flow rates and circuit management practices.

\section{Methods}

Databases of reviews were searched for similar metaanalyses and none were found. A preliminary literature search identified that the majority of studies were observational in nature being either primary observation studies or contained as sub-analyses of randomised studies. Given that our goal was to identify factors and interventions and develop hypotheses for future studies, inclusion of observational evidence was deemed acceptable. Consequently a systematic review strategy was developed following the MOOSE guideline statement for Meta-Analyses and Systematic Reviews of Observational Studies [8].

\section{Search strategy}

The search strategy was developed by an experienced researcher (MB) and assistance provided by library staff. We searched Pubmed (MEDLINE) and Ovid EMBASE libraries to $29^{\text {th }}$ February 2016 with no restrictions utilising keywords, variant spellings and wildcards (Table 1). Manual review of references from included studies and potentially relevant related citations was also performed.

\section{Included studies}

All abstracts were imported into Zotero (version 4.0.28.8, George Mason University, Fairfax, VA, USA) and duplicate entries from different databases merged. Abstracts were screened independently by two researchers $(\mathrm{MB}, \mathrm{EW})$ for potential relevance after which full text versions of the papers were obtained for all potentially relevant studies. 
Table 1 Search Strategy

Title and Abstract Search
OR CWD OR CWH OR CWHD
Title and Abstract Search/MeSH Terms

$\mathrm{OR}$

continuous venovenous OR continuous veno-venous OR continuous veno venous

AND haemodiafiltration OR haemodiafiltration OR hemofiltration OR haemofiltration OR ultrafiltration

AND

extracorporeal circulation OR circuit* OR filter* OR vascular access OR access catheter OR catheter OR securement OR flush OR lock* OR haemofilter or haemofilter or blood flow or ultrasound OR vein

AND

safety events OR bleeding dislodgement or disconnect* OR recirculat* OR dysfunction OR failure OR life* OR interruption OR survival OR thrombosis OR clot* OR coagulant* OR "blood coagulation" [MeSH Terms]

OR clearance OR flux OR homeostasis OR acid base OR strong ion difference OR effectiveness OR efficacy or biocompatibility OR body habitus OR obesity OR patient position OR physiotherapy OR physical therapy OR mobilisation OR education OR training OR experience

* $=$ wildcard search character

Studies were included if they documented filter life in hours with a comparator other than anti-coagulation intervention. All studies comparing anticoagulation interventions were searched for regression or hazard models pertaining to other variation in filter life. Abstracts detailing proceeds of meetings and conference abstracts were merged with studies by the same authors if the results were clearly duplicate entries and otherwise included. Foreign language articles were converted to English using Google Translate [9].

\section{Excluded studies}

The following studies were excluded: Abstracts of pharmacokinetic CRRT studies, studies on cytokine mediators, micronutrients or renal recovery as well as reviews and prior meta-analyses.

We also excluded studies that solely documented filter life in a population without any comparators or relationship to independent variables, studies describing arbitrary levels of filter life without a baseline group (e.g. arbitrarily comparing survival curves between 'short' and 'long' filter life) and results that divided filter life into dichotomous time periods without specifying hours per filter or similar variations such as numbers of filters per day. In these cases authors were contacted regarding obtaining original data. Bench studies or studies involving animals were also excluded.

\section{Data extraction \& statistical methods}

Filter life and basic study data were extracted directly into Comprehensive Meta-Analysis version 3.3.070 [10] while study details were entered directly into Revman version 5.3 [11] after exporting citations from Zotero. Multiple regression covariates (using the full model where available) were converted to correlations using Rosenthal \& Rubin's r-equivalent method [12-14]; when comparison of means were also available we found this technique produced similar effect size estimates. If survival curves were presented without hazard ratios, these were extracted using methods detailed by Liu \& Hanley [15-18] utilising Engauge Digitizer version 6.2 [19] and $R$ version 3.0.2 with package survival $[20,21]$. As a last resort medians and interquartile ranges were converted to means using recognised procedures and results requested from the study author [22]. One author [23] provided original data for which a survival analysis was performed in $\mathrm{R}$ version 3.0.2 with package survival version 2.38-3 [21] utilising a Cox proportional hazards model and further pooled with the authors (MB) previously published data [24] to produce Kaplan Meier figures.

Comprehensive Meta-Analysis version 3.3.070 [10] was utilised to present varying effect size estimates as Odds Ratios (for risk of event data) or Hazard Ratios (for time to event data) depending on the source. A random effects model was used to combine similar variables for summary effect estimates. Where a sub-group has both Hazard and Odds Ratio effect size estimates, the estimates are discussed in the text.

Quality and risk of bias was assessed utilising the GRADE approach [25] as implemented in Revman version 5.3 [11] and a summary of findings table created using GRADEpro [25]. Heterogeneity was considered on pragmatic grounds from sources of variability in the study description and statistically when sufficient comparisons were present with an $\mathrm{I}^{2}$ statistic $<50 \%$ denoting low heterogeneity and $>80 \%$ denoting high. We graded risk of detection bias for observational studies according to the trial design with a lower risk attributed to large data sets reporting multiple factors and higher risk attributed to retrospective analysis of an intervention or cohort difference.

\section{Classification of studies}

The primary outcome was filter life. Factors associated with filter life were arbitrarily divided into patient factors, vascular access factors and circuit factors with subgroups within each level. Studies reporting multiple variables were included in more than one category. 


\section{Results}

Search results (Fig. 1)

A total of 819 abstracts were identified of which 364 were selected for full text analysis. The study selection process is outlined in Fig. 1. Characteristics of included studies are displayed in Tables 2, 3 and 4 . The most common reason for study exclusion was failure to describe filter life in hours. Figure 2 describes the overall bias summary of included studies. Bias summaries for individual studies are included with the forest plots. The authors of three studies provided clarifying information upon request and one author provided original data for reanalysis [23].

Fourteen studies contain filter life data related to vascular access properties. None of these were of high quality. Only one had a randomised design where the primary outcome was filter life [26], while a second randomised trial presented a post-hoc analysis of filter life by vascular access site [27]; neither was blinded. Two high quality randomised trials were identified in the literature search that did not report filter life related to vascular access but to catheter function; these are discussed in the relevant sections [28, 29].

Thirty-four studies contain filter life data related to circuit factors of which 13 had a prospective randomised design but only two were blinded. Twenty-four studies contain filter life data related to patient variables however the majority of indices of filter life were from subanalyses. No large high quality randomised studies existed. Only five studies in this analysis had a prospective randomised design [30-34] and of these only one described blinding of investigators.

\section{Overall filter life}

Amongst included studies from the entire systematic review where mean filter life was available, overall mean filter life was $21.92 \mathrm{~h}(n=7502, \mathrm{SD}=10.89)$.

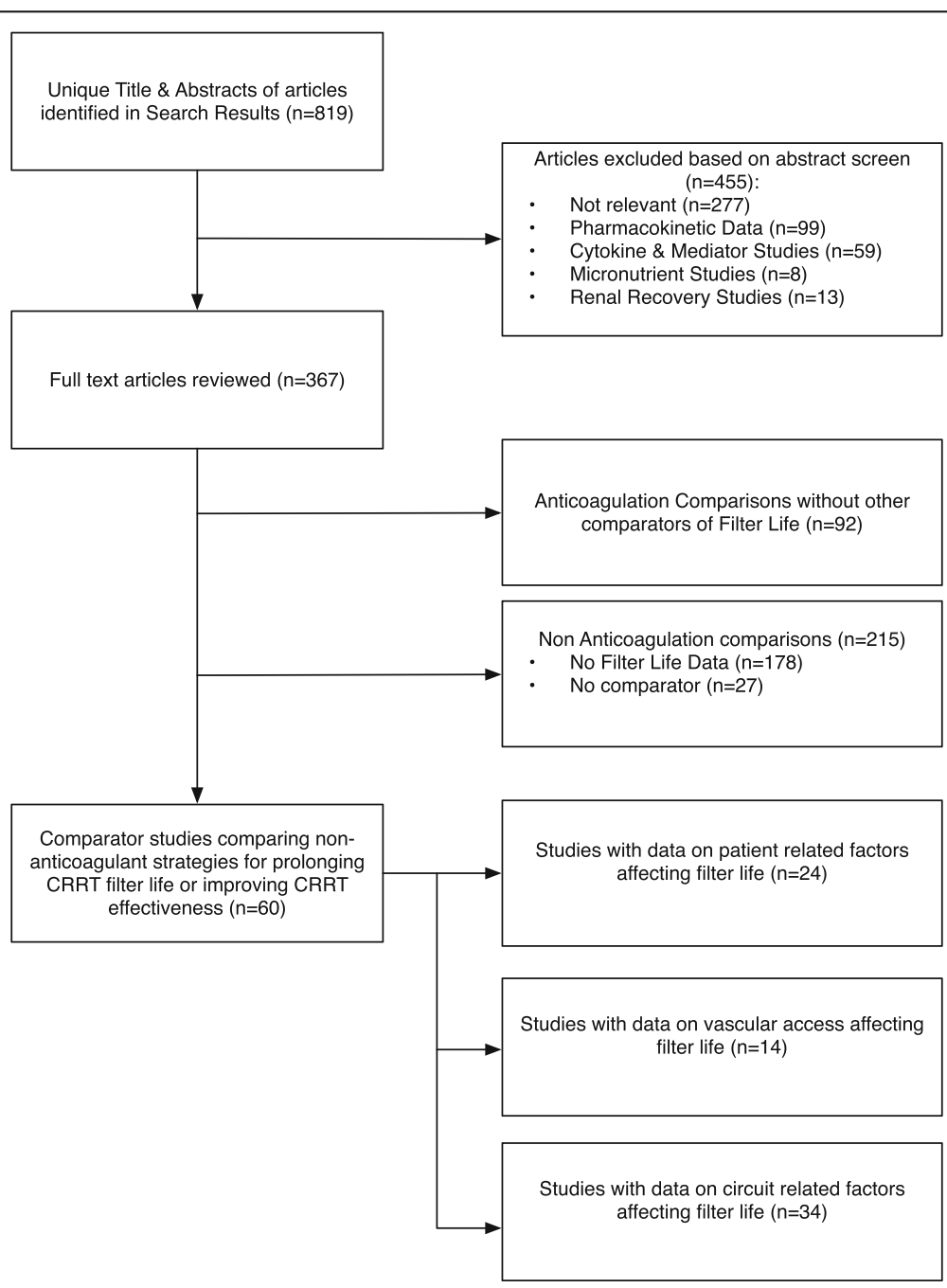

Fig. 1 Article flow through systematic review process 


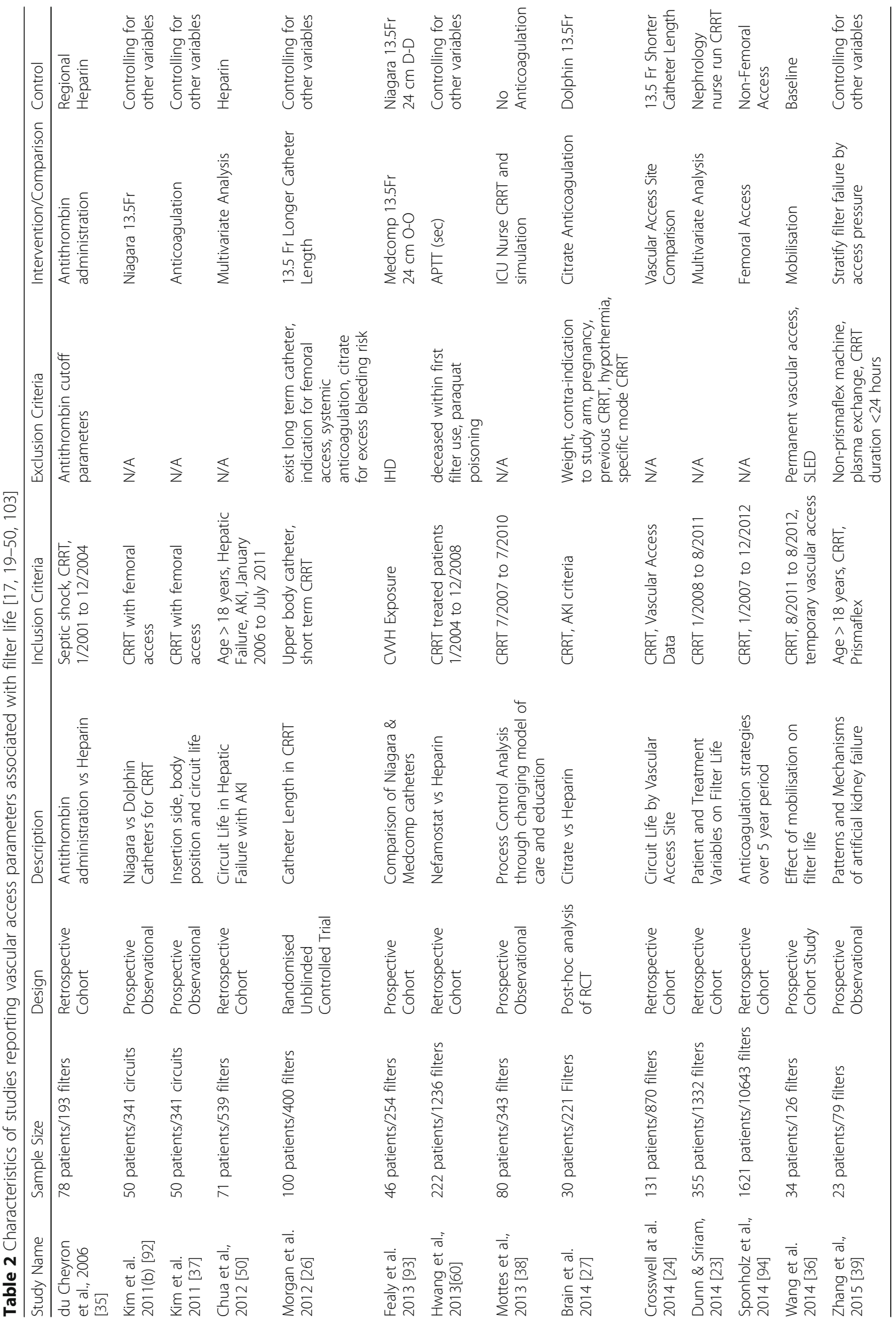




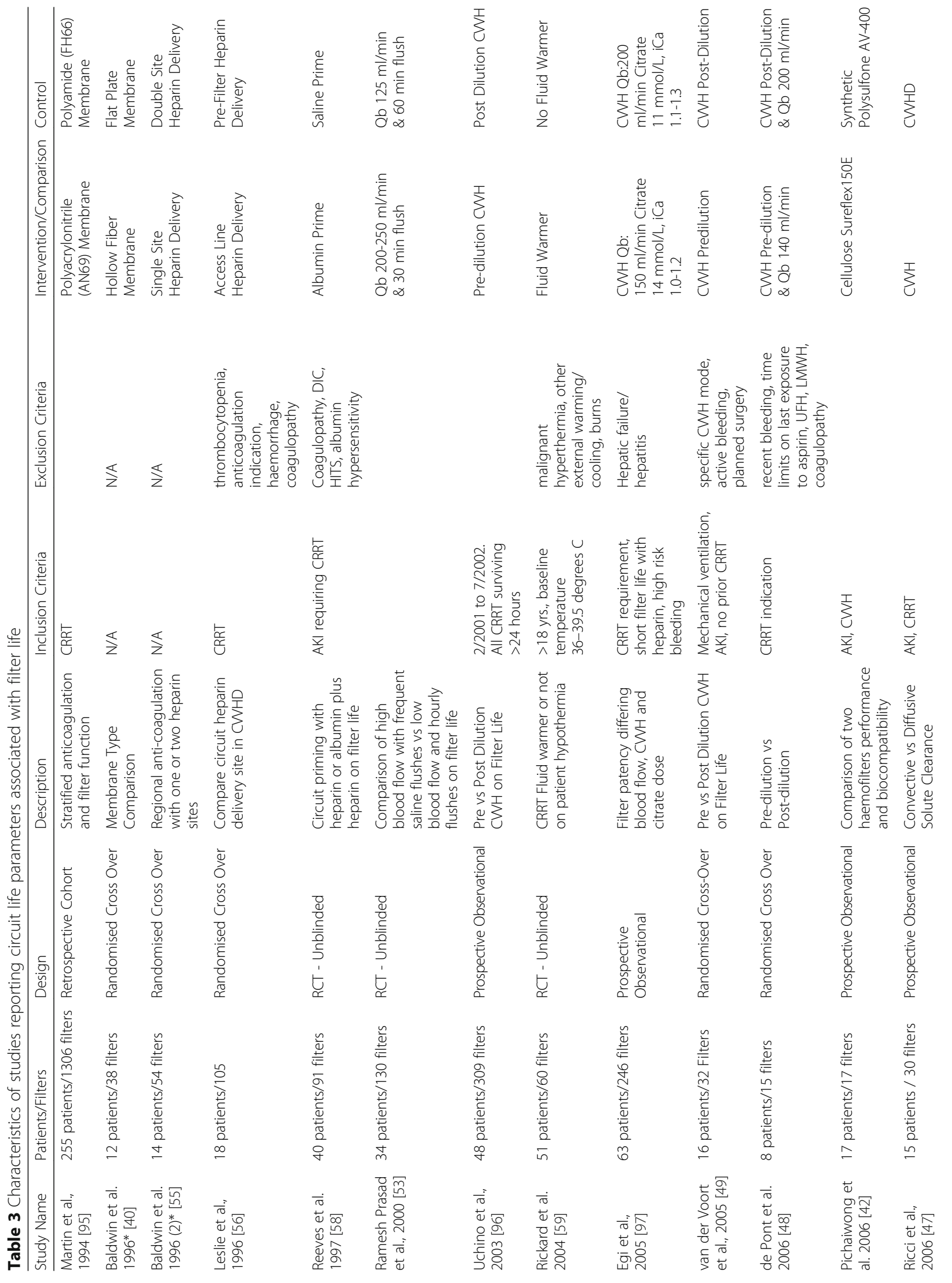




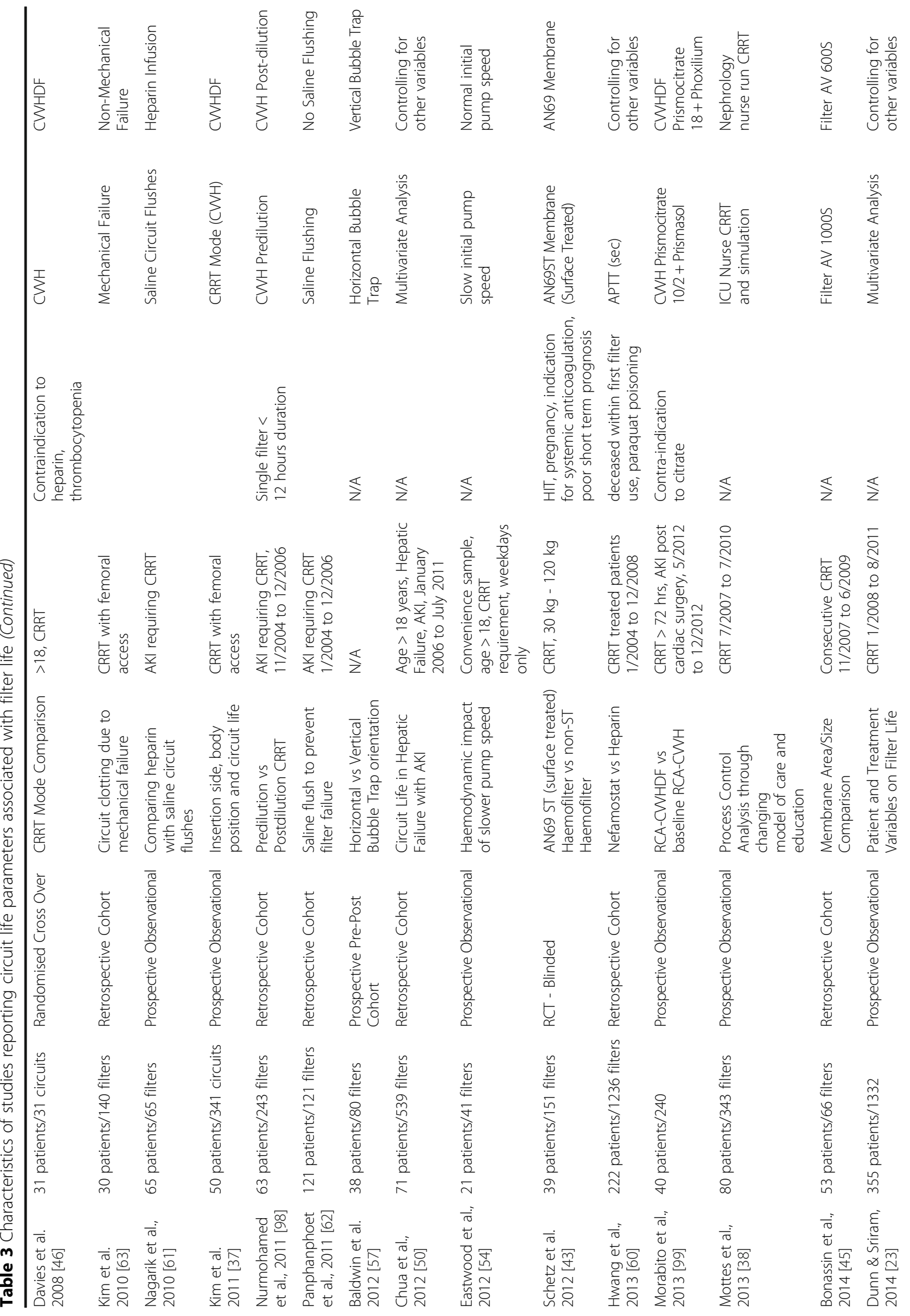




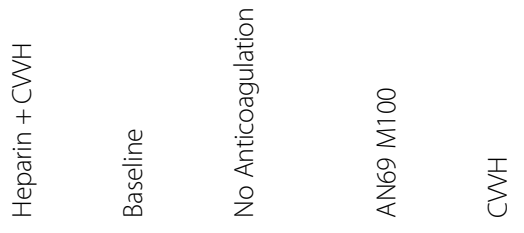

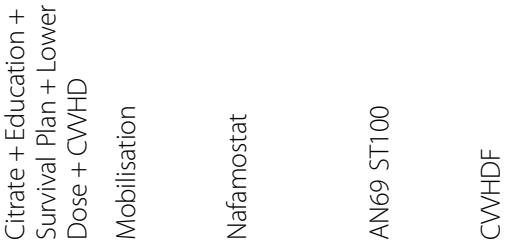

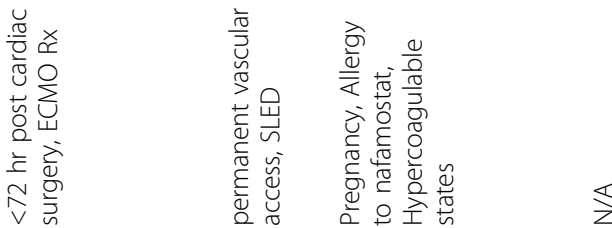

这产产。

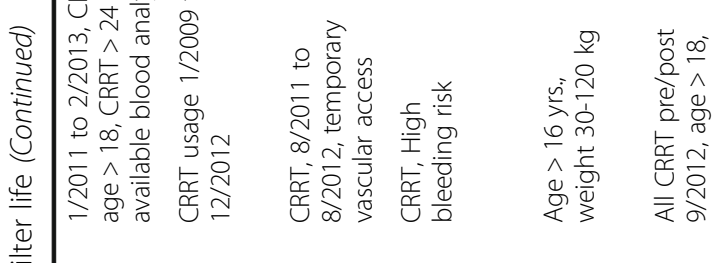

$\stackrel{ \pm}{ \pm}$

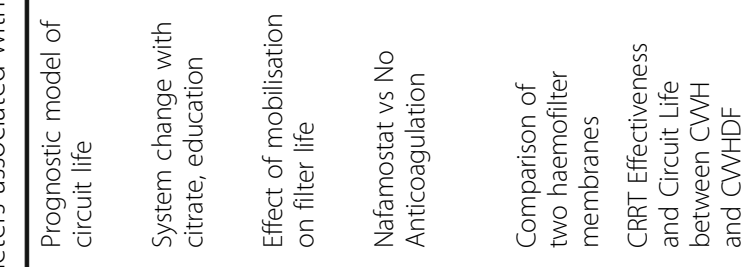

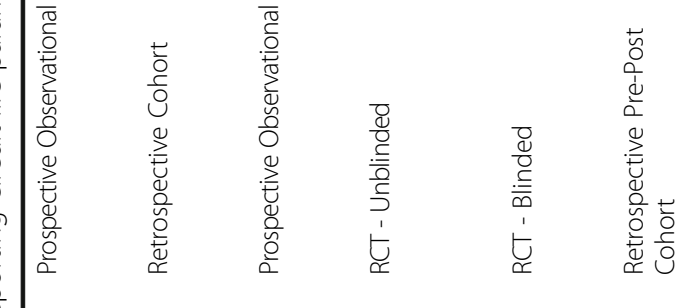

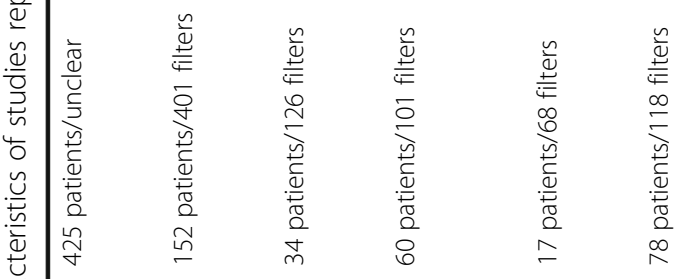

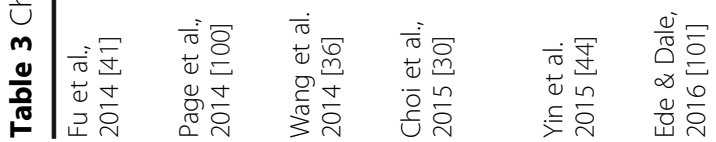




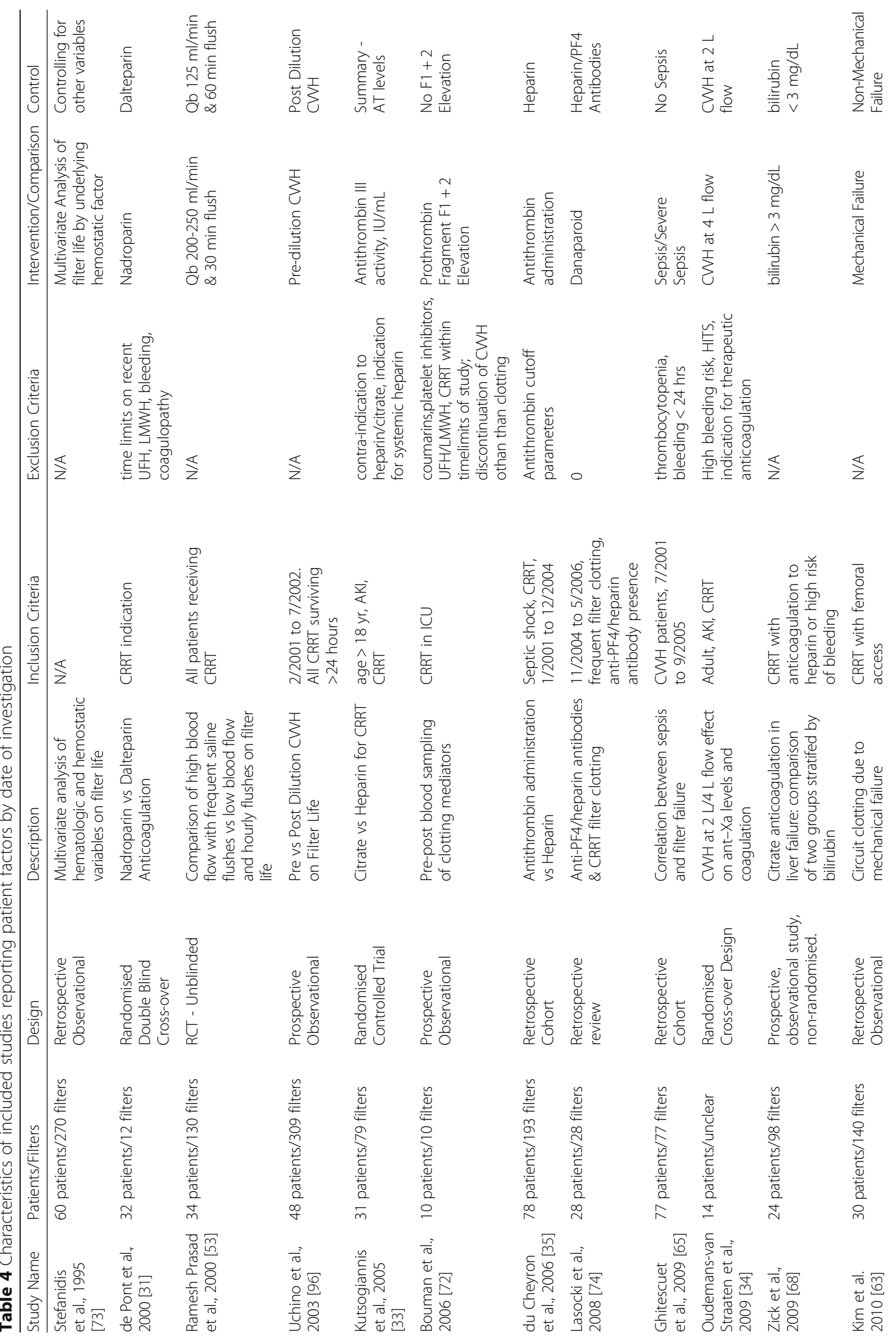




\begin{tabular}{|c|c|c|c|c|c|c|c|c|c|c|c|c|}
\hline 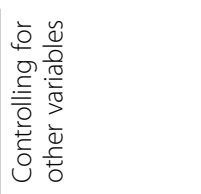 & 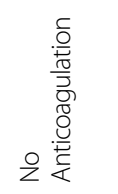 & 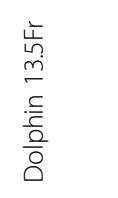 & 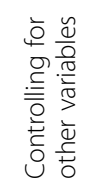 & 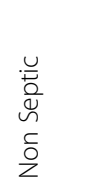 & 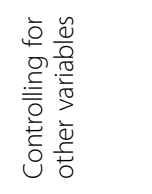 & $\begin{array}{l}\stackrel{\mathfrak{E}}{\overline{0}} \\
\stackrel{0}{\underline{I}}\end{array}$ & 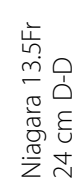 & 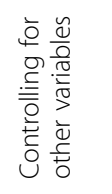 & 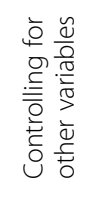 & 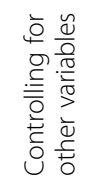 & 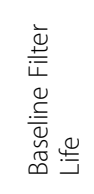 & 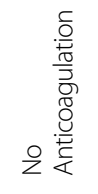 \\
\hline 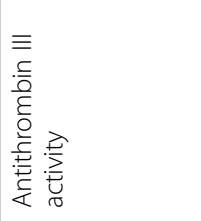 & 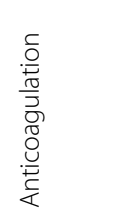 & 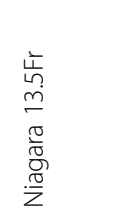 & 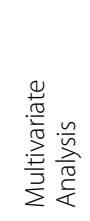 & $\frac{u}{\overline{0}}$ & 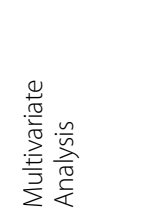 & 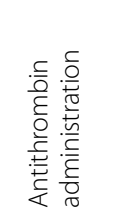 & 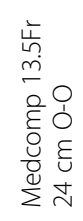 & 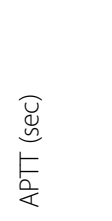 & 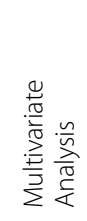 & 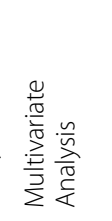 & 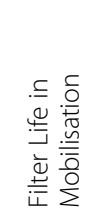 & 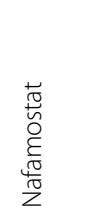 \\
\hline 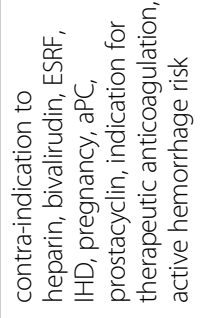 & $\frac{\pi}{z}$ & $\stackrel{\mathbb{z}}{z}$ & $\underset{\Sigma}{z}$ & $\stackrel{\mathbb{z}}{z}$ & 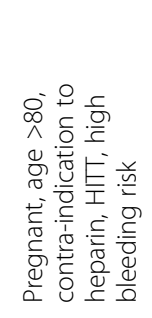 & $\frac{1}{z}$ & $\stackrel{9}{\underline{I}}$ & 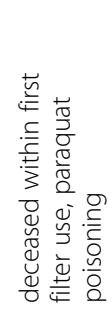 & 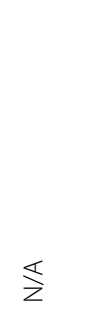 & 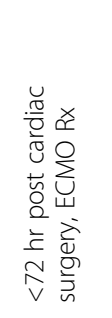 & 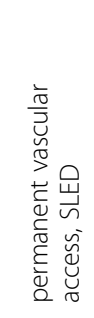 & 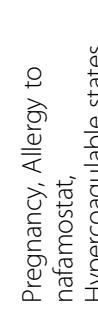 \\
\hline 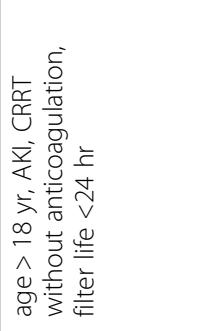 & 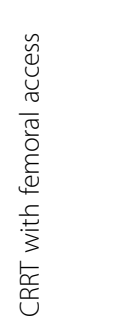 & 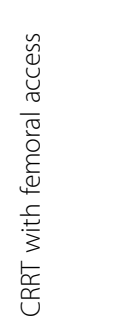 & 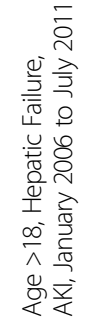 & 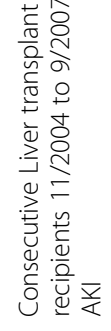 & 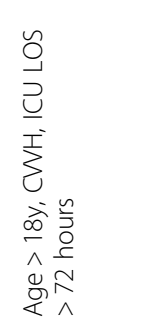 & 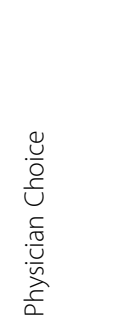 & $\sum^{I}$ & 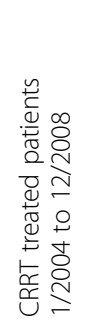 & 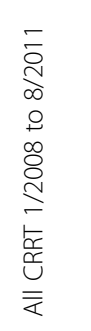 & 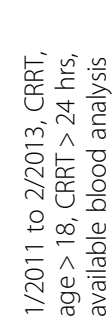 & 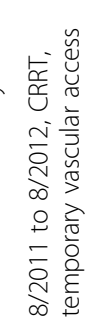 & 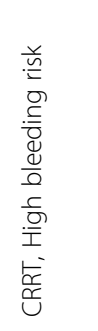 \\
\hline 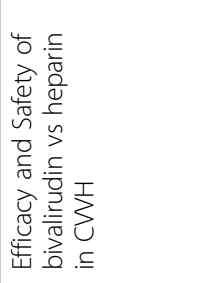 & 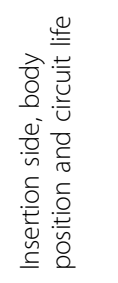 & 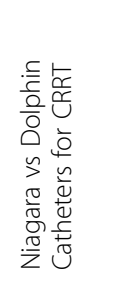 & 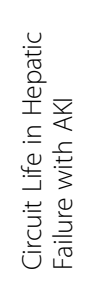 & 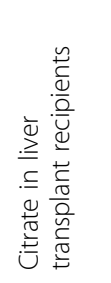 & 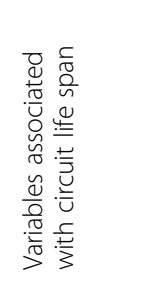 & 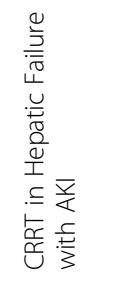 & 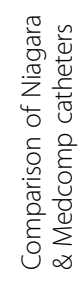 & 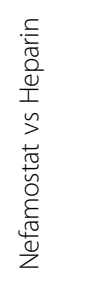 & 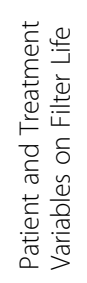 & 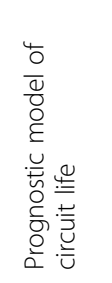 & 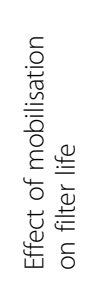 & 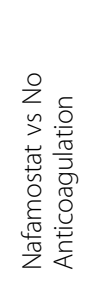 \\
\hline 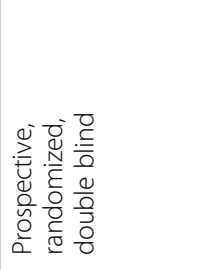 & 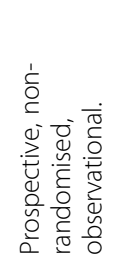 & 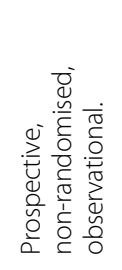 & 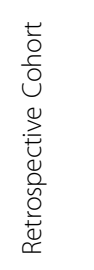 & 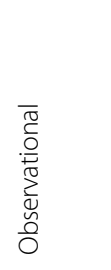 & 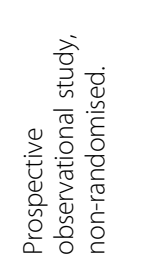 & 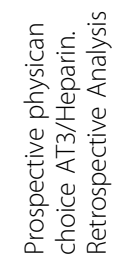 & 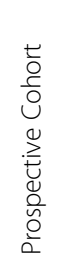 & 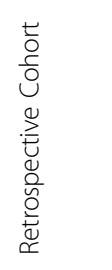 & 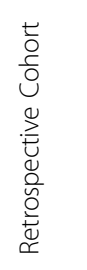 & 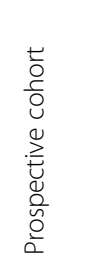 & 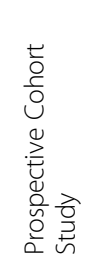 & 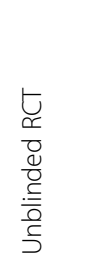 \\
\hline 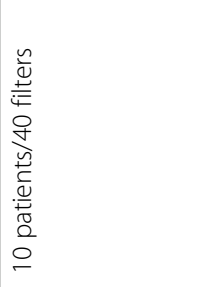 & 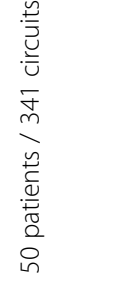 & 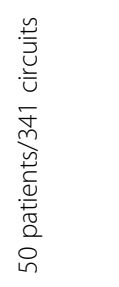 & 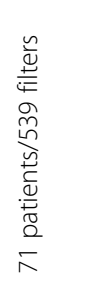 & 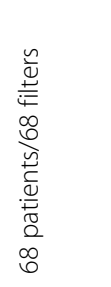 & 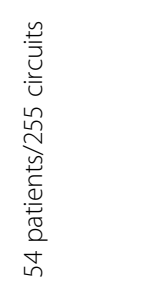 & 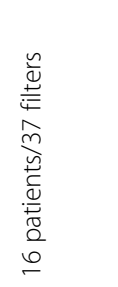 & 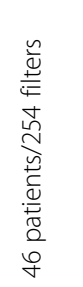 & 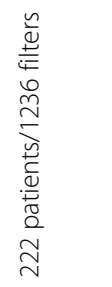 & 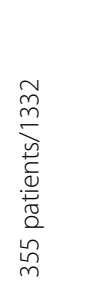 & 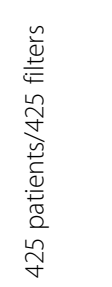 & 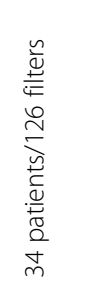 & 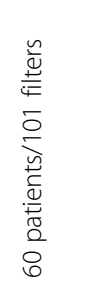 \\
\hline 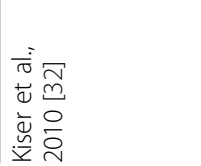 & 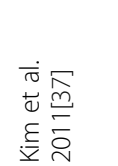 & 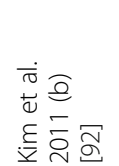 & 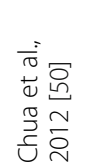 & 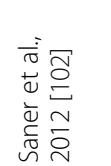 & 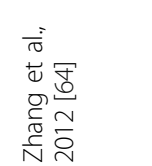 & 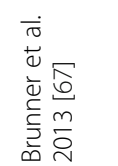 & 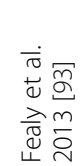 & 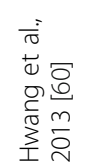 & 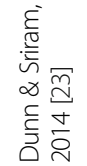 & 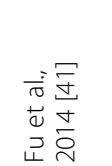 & 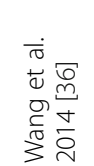 & 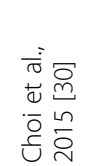 \\
\hline
\end{tabular}




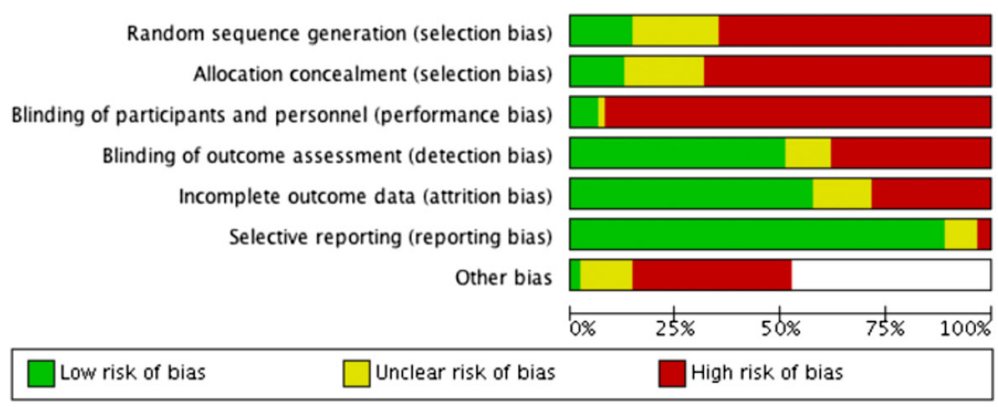

Fig. 2 Risk of Bias Graph. For non - randomised studies detection bias risk was graded by likely influence on findings

\section{Vascular access factors and filter life Access site and filter life}

Figure 3 displays grouped effect estimates for comparisons between vascular access sites. The femoral vein was the most common vascular access site utilised across studies that contained filter life data. Significant dispersion of estimates exists between studies comparing femoral and non-femoral access routes. No data existed on the order of catheter insertion sites in individual patients.

Of studies reporting internal jugular vs. femoral catheter sites, du Cheyron [35] in 78 patients favoured internal jugular access whereas the grouped effect estimate of studies reporting time to event outcomes trended toward the femoral site with an associated 27\% (95\% CI $-4 \%$ to $69 \%, p=0.092)$ increase in filter survival with low heterogeneity $\left(\mathrm{I}^{2}=24.8 \%\right)$.

Results comparing subclavian vs femoral catheters also suggested a trend associating improved filter life from femoral access whereas tunnelled semi-permanent catheters and direct connection to ECMO circuits were associated with longer filter life when compared to femoral access. Again statistical significance was influenced by choice of statistical model for the pooled effect with fixed effects models reaching significance.

Datasets made available from two studies [23, 24] were pooled to construct survival curves by filter site for 2173 filters. Subclavian access was associated with significantly worse filter life than femoral access whereas temporary internal jugular catheters was no different. Tunnelled access $(14.5 \mathrm{Fr})$ trended toward longer filter life while a direct connection to ECMO provided the longest filter life (Fig. 4).

Though not reporting filter life, an important subanalysis of a large multi-centre study of CRRT dose [29] suggested femoral catheters had limited impact on CRRT dose delivery compared to non-femoral catheters.

A single small study described patient activity and catheter site with filter life; Wang et al. [36] found at baseline non-femoral catheters were associated with longer filter life however this advantage did not persist with mobilisation.

\section{Access side and filter life (Fig. 5)}

Three studies provided comparison data on the side of vascular access. Results for femoral side were heterogeneous $\left(\mathrm{I}^{2}=82.8 \%\right)$ with the study by Kim [37] a significant outlier.

Of relevance to side selection is a multicentre randomised control trial that investigated time to catheter dysfunction as an outcome rather than filter life [28] between right or left jugular and femoral placement in intermittent haemodialysis and/or CRRT. This study found no significant difference in risk of dysfunction between right jugular and femoral sites (trend favoured right jugular) however left jugular performed significantly worse (adjusted hazard ratio vs femoral 1.89 (95\% CI $1.12-3.21, p<0.02)$ ).

\section{Catheter properties associated with filter life (Fig. 6)}

A single randomised comparison of catheter length [38] in great thoracic veins with confirmation of atrial tip placement vs superior vena cava tip positioning demonstrated superiority of longer (atrial) catheters. Importantly this study reported no difference in incidence of atrial or ventricular arrhythmias between the two catheter lengths.

Only one study in a paediatric population reported catheter size comparisons in relation to filter life [26] demonstrating only a weak signal. However the effect is likely greater given the report of a sub-analysis of the large RENAL dataset [29] demonstrating achievement of increased renal dose with larger catheters.

Extremely negative access pressures were associated with decreased filter life [39] in a single study.

\section{Catheter types association with filter life}

All studies reporting differences between temporary vascular access devices used a before-after design in an intensive care unit. Across all studies a trend favouring the Niagara catheter (Bard Canada) being associated with longer filter life was observed however the pooled effect was not significant. Tunnelled cuffed semi-permanent devices trended towards superior filter life compared to temporary devices in each analysis (Figs. 3, 4, and 7) 


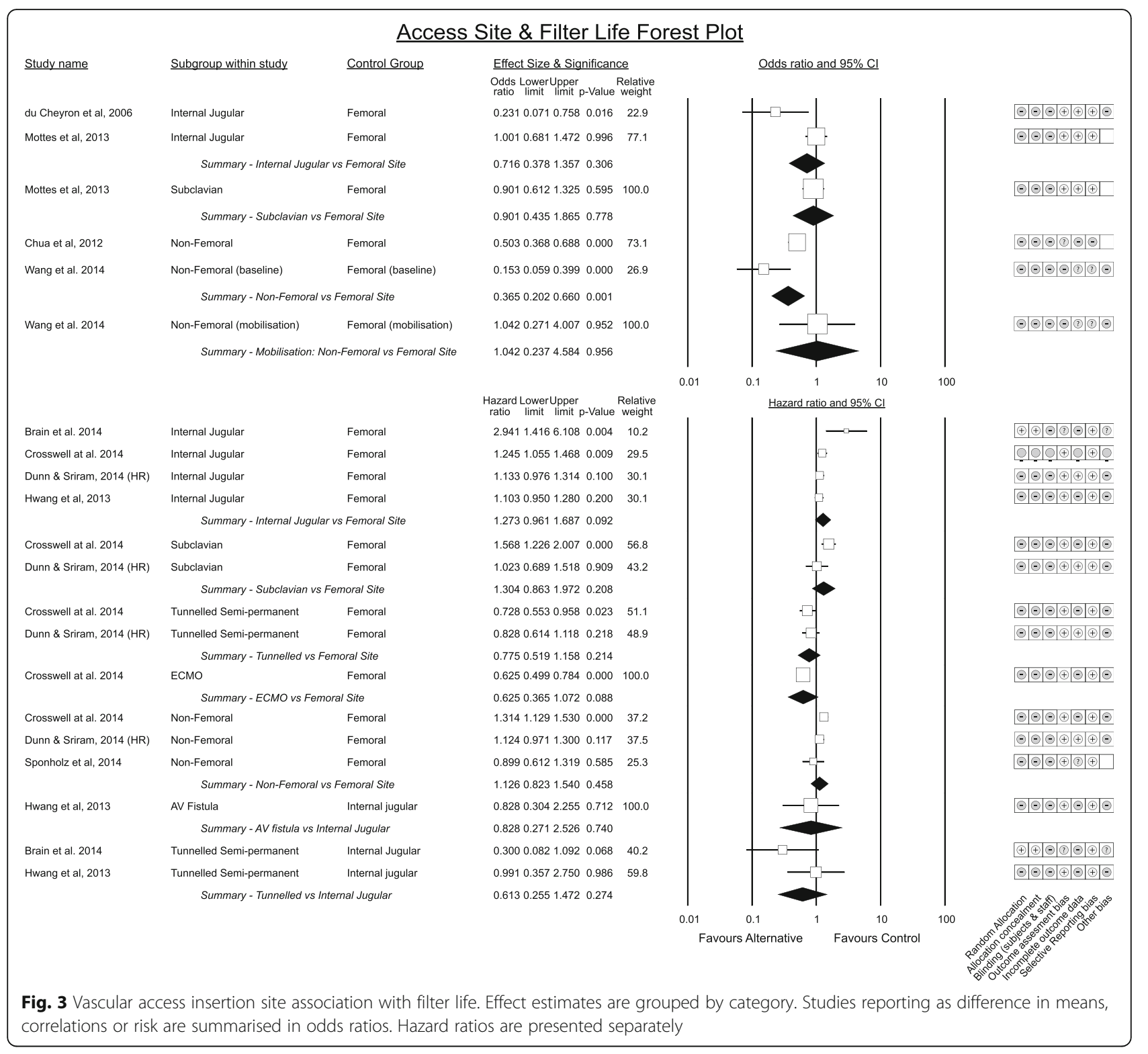

- often these catheters have larger diameters $(14.5 \mathrm{Fr}$ to $15.5 \mathrm{Fr})$.

\section{Circuit factors associated with filter life Haemofilter membrane characteristics (Fig. 8)}

Studies comparing haemofilter membranes spanned several advancements in membrane technology over a 22 -year period. One early randomised study [40] demonstrated an advantage of hollow fibre membranes over flat plate haemofilter configurations for filter life while the remainder analysed contemporary hollow fibre membranes. Numbers of studies for each membrane comparison were small.
A trend favouring polysulfone membranes ahead of cellulose triacetate in being associated with longer filter life was apparent in one multiple regression analysis [41] but a newer modified cellulose membrane showed no difference [42]. No significant difference in filter life existed between the non-surface coated AN69 membrane and a polysulfone membrane in one study [38]. Interestingly newer surface treated (heparin binding and potentially more biocompatible) AN69ST membrane did not show any advantage in filter life over the non-surface treated AN69 in two randomised studies [43, 44].

Classically diffusive transport improves with haemofilter membrane area and anecdotally increased membrane area 


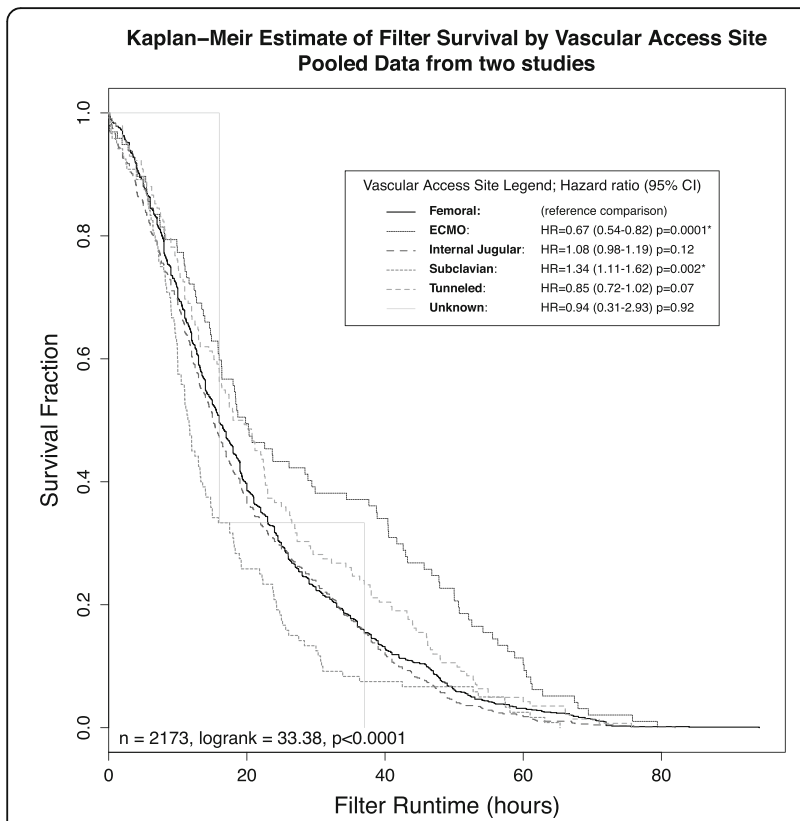

Fig. 4 Pooled survival analysis of filter life by vascular access site from 2173 filters from two studies $[23,24]$. * signifies curves that demonstrate a statistically significant difference to femoral access. Sites denote temporay catheters except for tunnelled semi - permanent devices and ECMO

prolongs filter life however a single study comparing membrane area did not demonstrate an advantage [45].

\section{CRRT mode, Pre vs post dilution and CRRT dose (Fig. 9)}

The optimum modality of CRRT for filter life was consistent across nearly all studies including two randomised [46, 47] trials with CVVHD-F (or CVVHD [47]) associated with a $44 \%$ lower failure rate compared to CVVH (Fig. 9). Statistical heterogeneity was low $\left(\mathrm{I}^{2}\right.$ for event risk comparisons $25.5 \%, p=0.058$; hazard ratio comparisons zero) and the result reached significance in time to event analysis $(p<0.001)$ with minimal dispersion.

Whether CVVH with pre or post dilution is superior was less clear with more heterogeneity $\left(\mathrm{I}^{2}=48.6 \%\right)$ across risk results and no overall trend $(p=0.245)$. Of the two small randomised studies in this group $[48,49]$ only van der Voort et al. purely compared pre vs post dilution and favoured pre-dilution to prolong filter life.

Higher CRRT dosage, prescribed ultra-filtration rate and fluid removal rate were not associated with differences in filter life amongst the retrospective analyses that reported this outcome [36, 41,50]. Although not directly reporting filter life, the results of two large multi-centre trials of RRT intensity are relevant in regards to CRRT dose suggesting that higher intensity RRT may be associated with decreased filter life; the RENAL Investigators [51] used $0.93 \pm 0.86$ filters per day in the high intensity group vs $0.84 \pm 0.81$ in the lower group $(p<0.001)$. Similarly Palevsky et al. [52] report 3178 CRRT treatments in 563 patients in the intensive arm vs 2789 in 561 patients in the lower intensity group.

\section{Blood flow and filter life (Fig. 10)}

Higher blood flow rates have been hypothesised to prolong filter life by minimising stasis within the blood path [3] however results vary across studies. Of the three studies with randomised design none detected a difference though blood flow was not the primary outcome in the comparison by Choi et al. [30] and the studies by Ramesh Prasad et al. [53] and de Pont et al. [48] did not solely assess blood flow.

Though Mottes [38] did not show a significant association between blood flow and filter life, the pooled effect of studies contributing to the hazards model favoured higher blood flow ( $\mathrm{HR}=0.942, p=0.009, \mathrm{I}^{2}=25.8 \%$ ). This equates to a $5.8 \%$ increase in filter survival for each $10 \mathrm{ml} / \mathrm{min}$ increase in blood flow however as none of

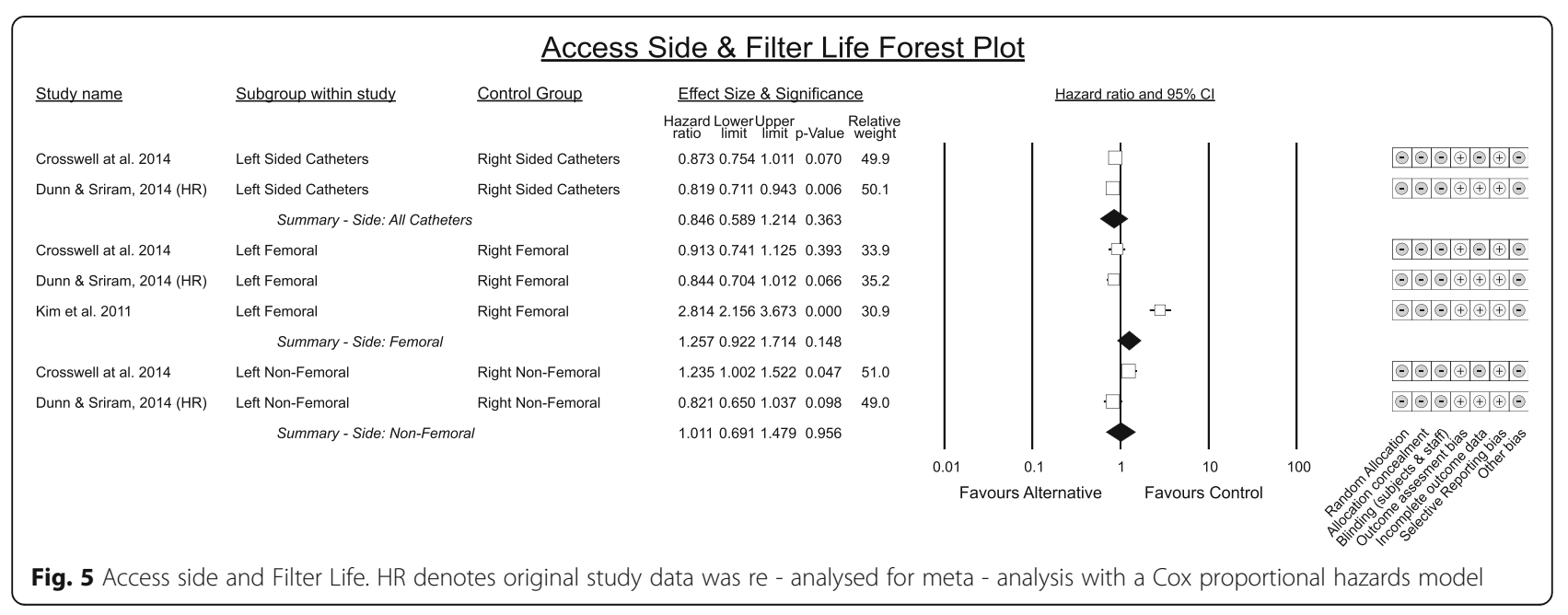




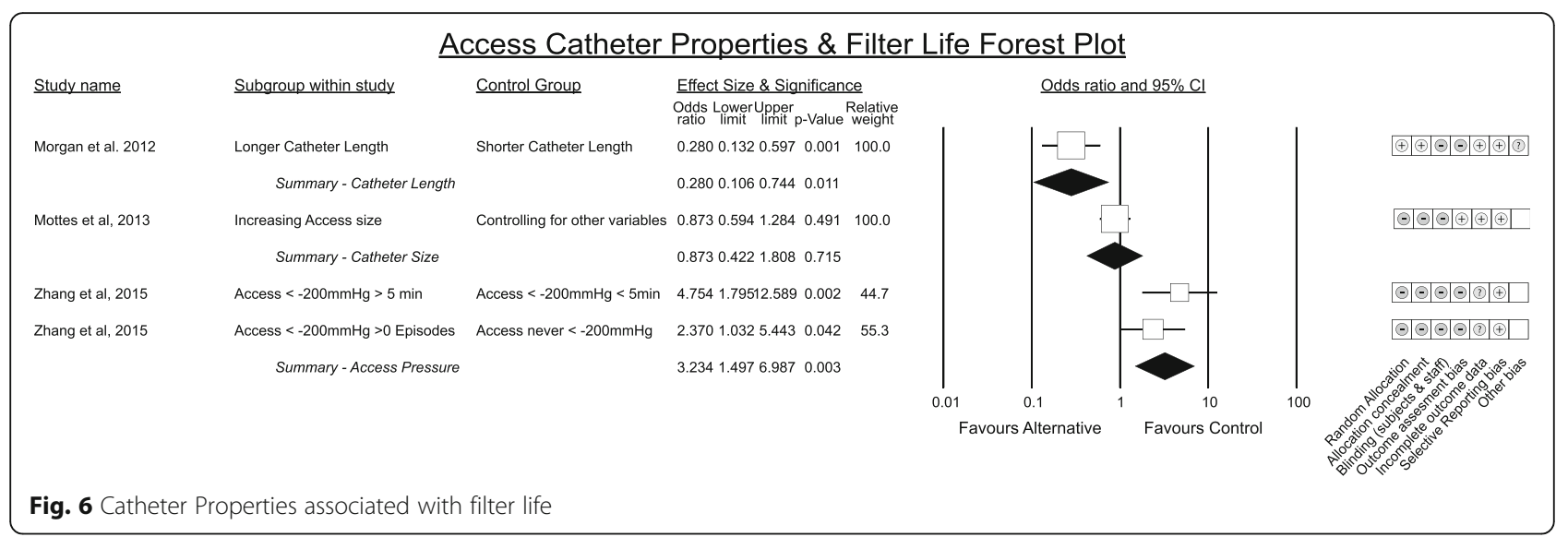

these studies were designed to directly compare low and high blood flow, this result should be considered supportive only.

The single study [54] investigating a gradual step up of initial blood pump speed to $200 \mathrm{ml} / \mathrm{min}$ over a shorter 4 min period vs a $10 \mathrm{~min}$ period found no benefit on patient haemodynamic parameters and a trend toward worse filter life at the slower step up.

\section{Blood path interventions associated with Filter Life}

Two small studies showed no benefit from different sites of heparin delivery $[55,56]$. No benefit was observed using a modified horizontal bubble trap on the return line [57], priming the circuit with albumin before use [58] to improve biocompatibility or by the presence or absence of a fluid warmer on the return blood path [59].
Saline flushing of the circuit was not beneficial however the only randomised study [53] simultaneously compared differences of blood flow. The remaining studies [60-63] utilised saline flushes in patients with a coagulopathy that contra-indicated use of heparin.

\section{CRRT system management and staff education interventions (Fig. 11)}

The number of alarms and an arbitrary definition of CRRT mechanical failure were both associated with worse filter life in two small studies $[36,63]$. Education around overall CRRT management with a structured simulation event was beneficial in two studies though only the study by Mottes et al. [38] purely assessed focussed education alone without other interventions.

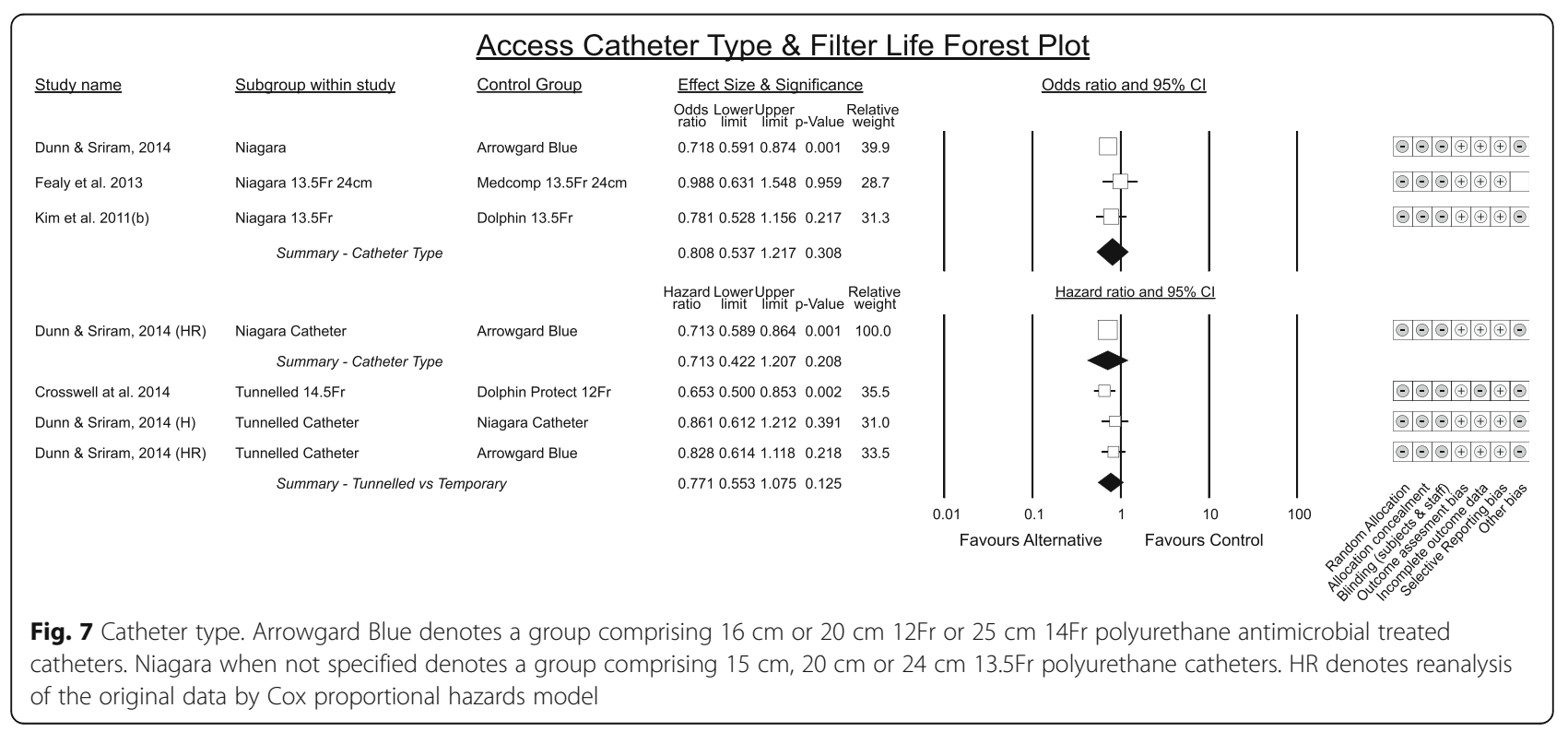




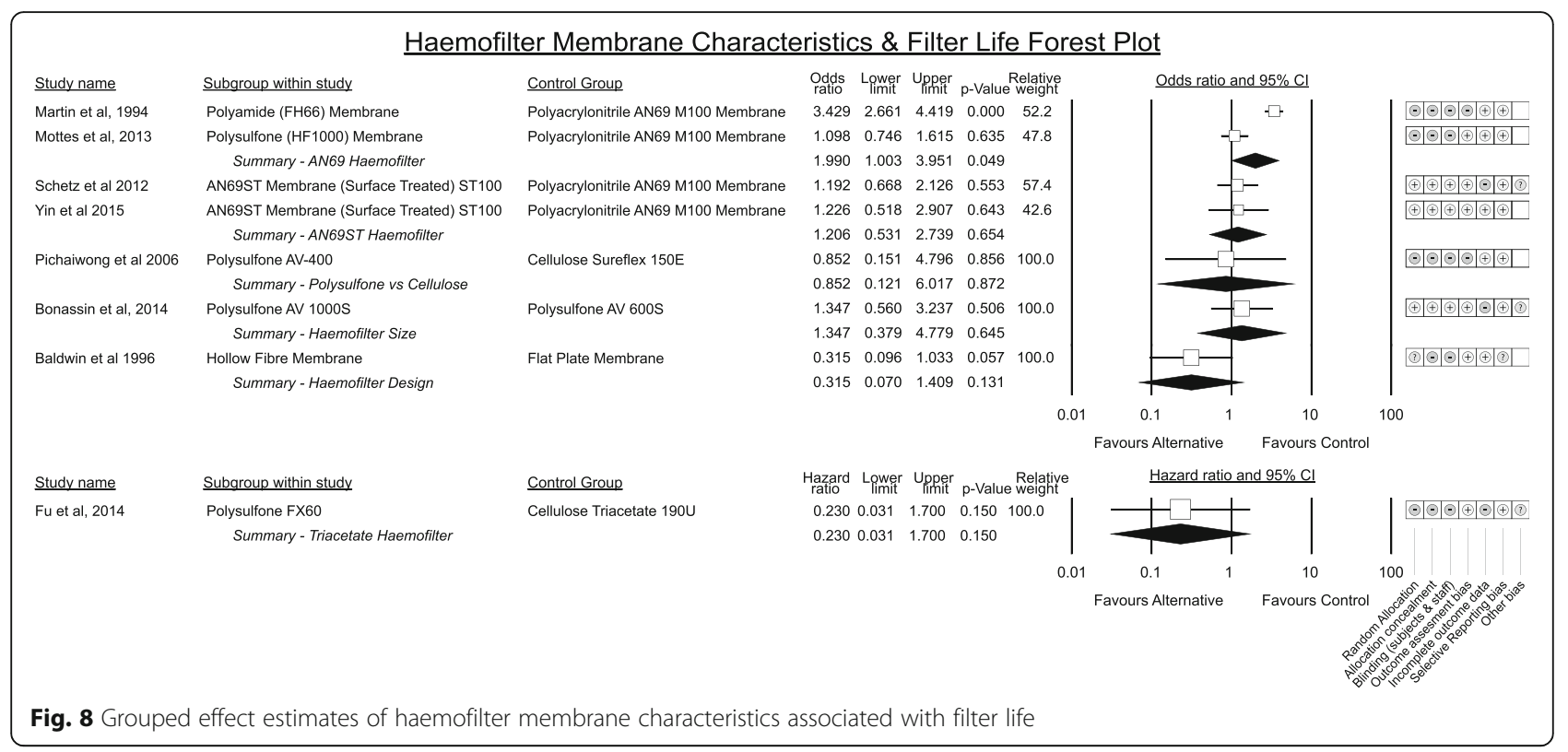

\section{Patient factors associated with filter life Patient factors}

Figure 12 presents grouped effect size estimates for patient factors associated with CRRT filter life. Among baseline factors increasing patient age and blood pressure were not associated with a difference in filter life however male sex trended toward shorter filter life with the pooled hazard estimate nearly reaching statistical significance though heterogeneity was moderate $\left(p=0.065, \mathrm{I}^{2}=54.4 \%\right)$.

Increases in body temperature demonstrated a nonsignificant signal toward association with shorter filter life in one study with a $14.9 \%$ (95\% C.I. $-1.7 \%$ to $34.4 \%$ ) increase in the failure rate per degree Celsius elevation [64]. Another single study suggested that presence of mechanical ventilation was associated with worse filter life while vaso-active drug therapy was an advantage [50].

\section{Patient pathology (Fig. 12)}

The most common pathology reported was sepsis. In general studies reported sepsis to have a negative effect on filter life with Ghitescuet [65] suggesting septic shock and sepsis fall on a continuum to reduce filter life further however the effect did not reach significance.

Filter life in the setting of liver failure with bilirubin > $3 \mathrm{mg} / \mathrm{dL}$ nearly reached significance for being associated with worse filter life. Not included in the forest plot due to the number of contrasts and no attempt to control for other variables is a study by Agarwal et al. [66] which contrasted anticoagulation free filter life in coagulopathic patients with acute liver failure, decompensated chronic liver disease, post liver transplant recipients, sepsis or haematological disorders. They found that haematological disorders had significantly longer filter life $(\bar{x}=21.7 \pm 19.7 \mathrm{~h})$ however all other groups demonstrated poor filter life with mean duration less than $12 \mathrm{~h}$. The most comprehensive description of patient factors interacting with filter life in acute liver failure or decompensated liver disease is found in Chua et al. [50] where MELD score, APTT, bilirubin, mechanical ventilation, platelet count and INR were associated with filter life in this population. Discussions regarding filter life and anti-coagulation in liver failure patients requiring CRRT are the subject of several studies [50, 66-71] and growing support is emerging for the safety and efficacy of citrate in this population [70].

\section{IIIness severity (Fig. 12)}

Illness severity scoring systems demonstrated heterogeneous association with filter life effect. The summary effect for increasing APACHE II and III $\left(\mathrm{I}^{2}=57.2 \%\right)$ scores demonstrated no association with filter life however higher SOFA scores and higher LOD scores were associated with decreased filter life in isolated studies.

\section{Biochemical parameters (Fig. 13)}

Only two studies displayed sub-analyses of biochemical abnormalities in association with filter life [41, 64]. A single study suggested lactate concentration displayed an association between high lactate and shorter filter life with a $14 \%$ (95\% C.I. 3\%-23\%) increase in failure rate per $1 \mathrm{mmol} / \mathrm{L}$ increase in lactate.

Two studies suggested higher ionised calcium was associated with shorter filter life (neither study was using 


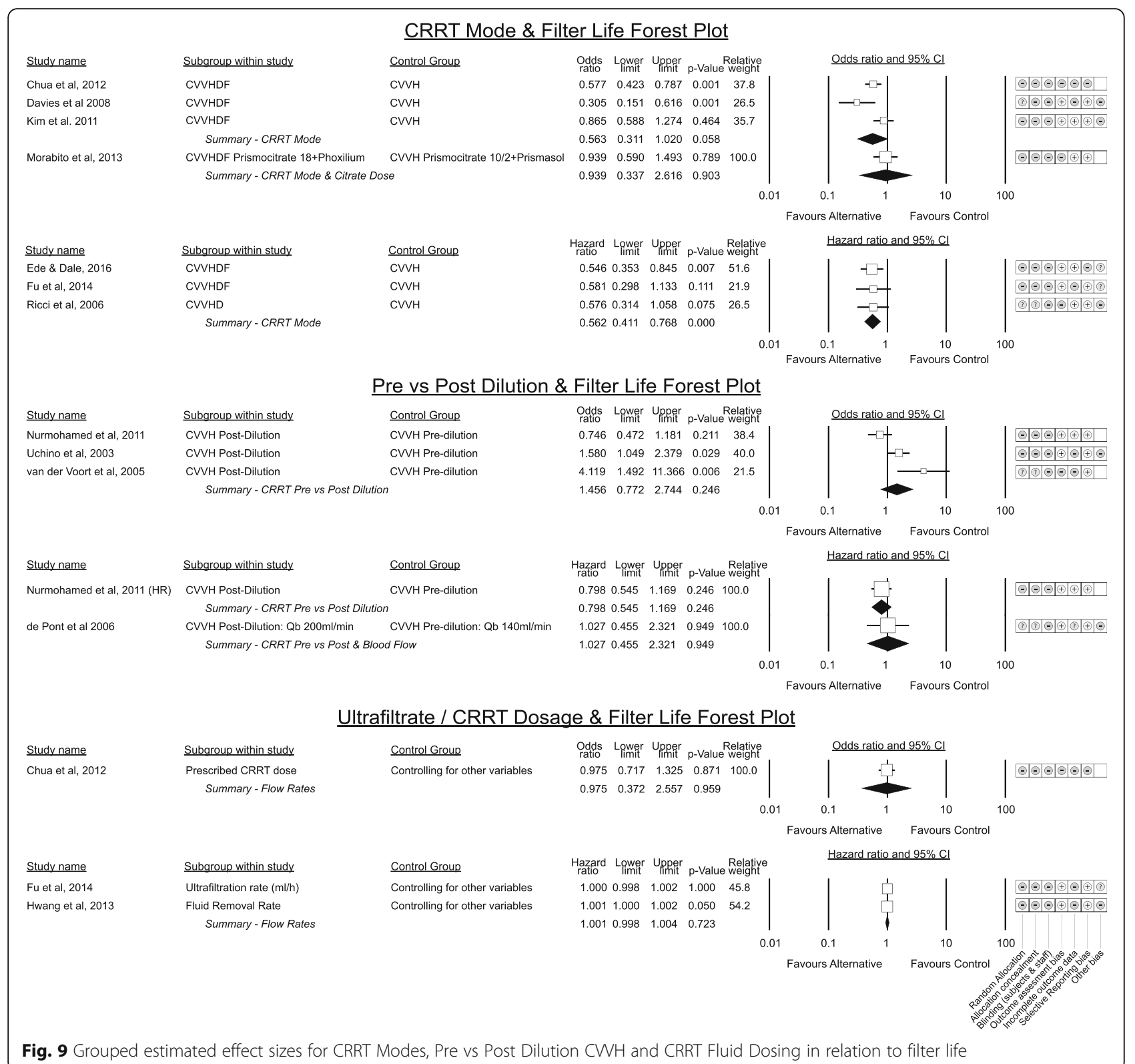

citrate anticoagulation) however the effect direction was not consistent.

Lower $\mathrm{pH}$ was associated with longer filter life equating to a $59 \%$ (95\% C.I. $10 \%$ to $59 \%$ ) increase in filter survival rate per 0.1unit fall in $\mathrm{pH}$. Zhang et al. [64] also demonstrated statistical significance between KaplanMeier curves for $\mathrm{pH}$ above or below 7.35 however interactions between $\mathrm{pH}$ and other patient factors are not explored.

\section{Blood parameters (Fig. 13)}

Blood count parameters demonstrated no significant association between haemoglobin (or haematocrit) measurements and filter life. There was inconsistency between higher platelet counts and shorter filter life; amongst results reported as odds ratios the summary effect for higher platelet counts reached statistical significance though heterogeneity was moderate $\left(p<0.0005, \mathrm{I}^{2}=53.5 \%\right)$ whereas the result for studies reporting a hazard ratio was not significant. A single study suggested higher neutrophil counts were associated with decreased filter life [41].

Receipt of a platelet or packed red cell infusion were both associated with a reduction in filter life though platelet infusion did not quite reach statistical significance.

\section{Coagulation parameters (Fig. 14)}

A positive association between APTT and filter life was observable amongst studies reporting as odds ratio 


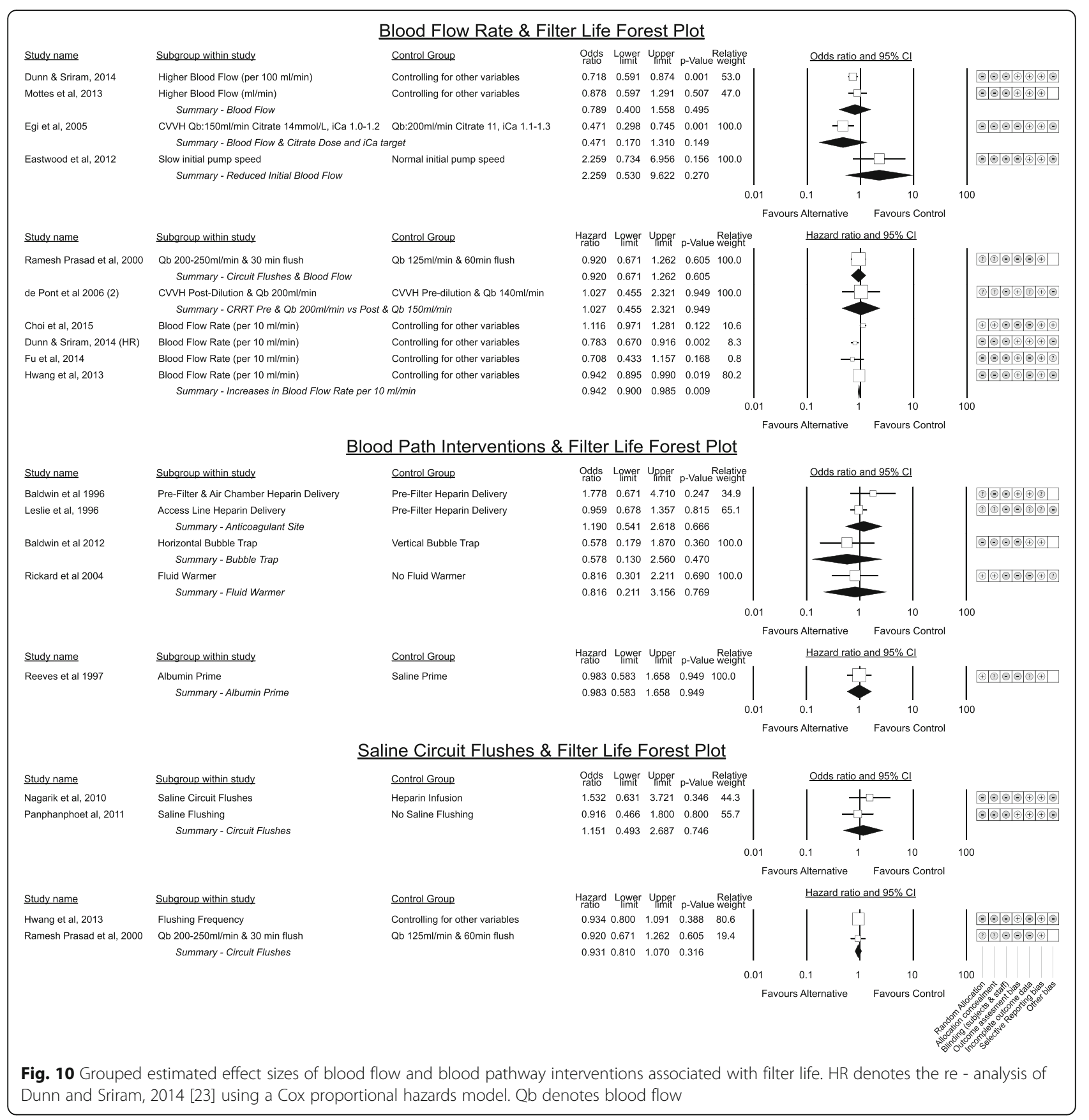

studies $(p=0.034)$ with a $1 \mathrm{~s}$ increment increasing the odds of filter survival by 1.17 . However an inconsistent trend toward shorter filter life reached significance for pooled hazard ratios though clinically insubstantial (odds of failure increase by 1.004 for each second increase). Heterogeneity for APTT was moderately high $\mathrm{I}^{2}=75.9 \%$. INR and prothrombin time (PT) subgroups were inconsistent in effect direction. Utilising elevations in prothrombin fragment $\mathrm{F} 1+2$ to measure anticoagulation had a positive association with increased filter life [72].
Fresh Frozen Plasma (FFP) administration was associated with a non-significant increase in the failure rate however this was only reported in one study [53].

Of interest were studies [32, 33, 35, 67, 73] reporting heparin resistance from low anti-thrombin III levels (AT-III). Higher AT-III levels trended to longer filter life, reaching significance in one study [33] while correction of AT-III deficiency was associated with a pooled $18.8 \%$ increase in filter life.

The presence of platelet-factor 4 antibodies (PF4) against heparin was significant in one study [74] which 


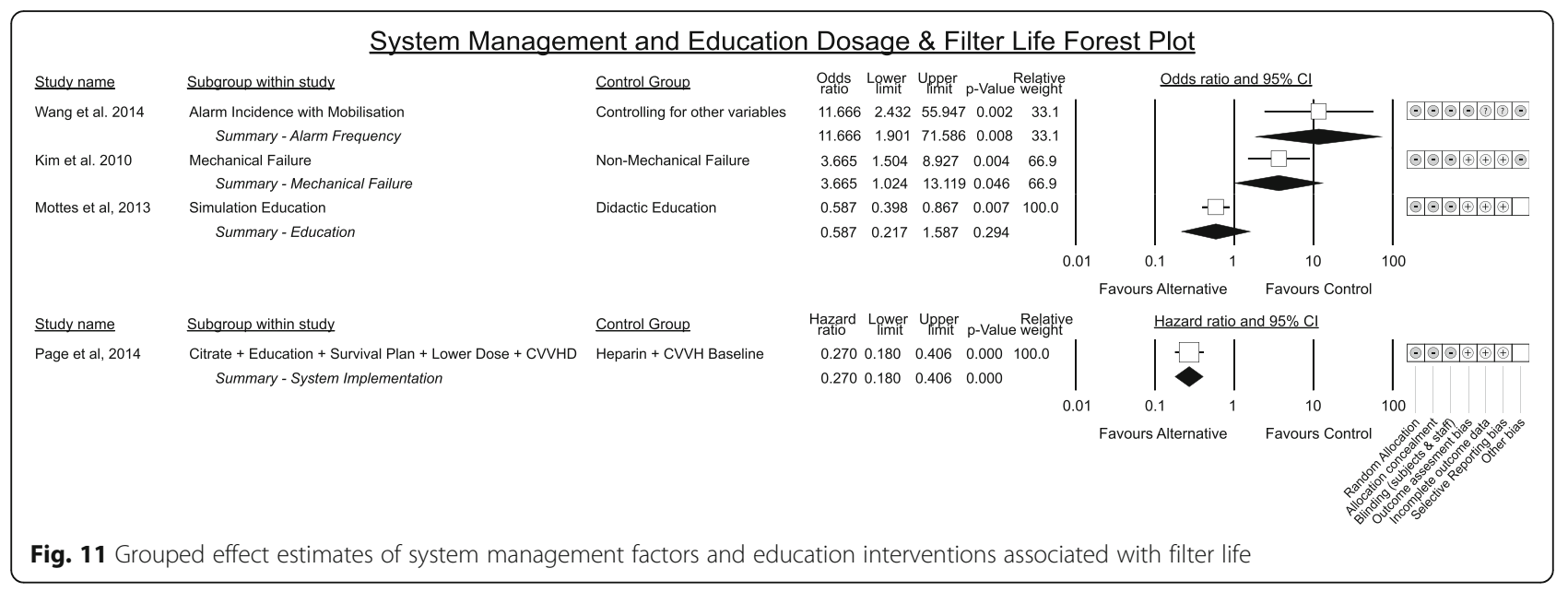

went on to demonstrate filter life comparable to nonPF4 positive patients after switching from heparin to danaparoid.

Higher fibrinogen levels were inconsistent in association with filter life with no effect reported by Stefanidis et al. [73] however a $50.8 \%$ increase in the failure rate for each $1 \mathrm{~g} / \mathrm{L}$ increase in fibrinogen reported by Fu et al. [41] $(p<0.005)$.

\section{Mobilisation and position (Fig. 14)}

A single study by Wang et al. [36] challenged the widely held belief that CRRT should be stopped for physiotherapy however the small numbers and trial design is open to observation bias. Another recent study by Toonstra et al. [75] affirmed that patient safety with CRRT and mobilisation can be maintained with care.

Kim et al. [37] explored the fraction of time patients spent in various positions with femoral vascular access and did not show a favoured side however that the supine position was used in nearly $50 \%$ of observations. Unfortunately, they did not report the interaction between position and left or right femoral catheters.

\section{Discussion}

This systematic review identified all published studies presenting comparisons of non- anticoagulant factors in relation to filter life. Overall filter life amongst included studies was less than $24 \mathrm{~h}$ with wide variation and well short of the multiple days that many filters can last. An interpretative summary of findings is presented in Table 5 .

\section{Vascular access}

Insertion of vascular access devices for CRRT is a very common occurrence however data to guide optimal catheter site is not strong. The heterogeneity in filter life between femoral and internal jugular siting suggest that unstudied factors such as timing of device in relation to severity of illness, patient factors (such as siting the device in a femoral location for sedation patients or upper body for upright patients) and operator experience may be important. Studies using time to catheter dysfunction $[28,76]$ as the outcome have similarly mixed results though the only randomised study found no difference [28] between femoral and jugular. Further analysis of large datasets may provide clarity - in particular studies are required that report the order of catheters.

Of interest was the result from Wang et al. [36] that patient mobilisation was not associated with any difference in filter life between femoral and non-femoral catheter sites. CRRT practice has typically minimised patient mobilisation but it could be safe and feasible without therapy interruption [36, 75]. More studies are needed to guide optimal siting of devices in recovering patients in order to allow ambulation while undergoing CRRT.

The randomised study by Morgan [26] demonstrating superiority of atrial over superior vena cava placement may suggest that studies where the femoral site was found superior could have found less difference if thoracic catheter location had been accounted for. Similarly, the advantage of tunnelled devices may result from the more frequent use of live $\mathrm{x}$-ray positioning to ensure optimal placement during insertion as opposed to only follow up $\mathrm{x}$-rays for tip placement for placement within intensive care units.

Offsetting any advantage to filter life of femoral or jugular catheter placement over subclavian access is the possibility of a lower infection risk at subclavian sites [77-79]. However subclavian access is associated with an increased risk of strictures with one study reporting this event in $50 \%$ of subclavian veins from short term temporary dialysis catheter placement [80]. Our conclusion is 


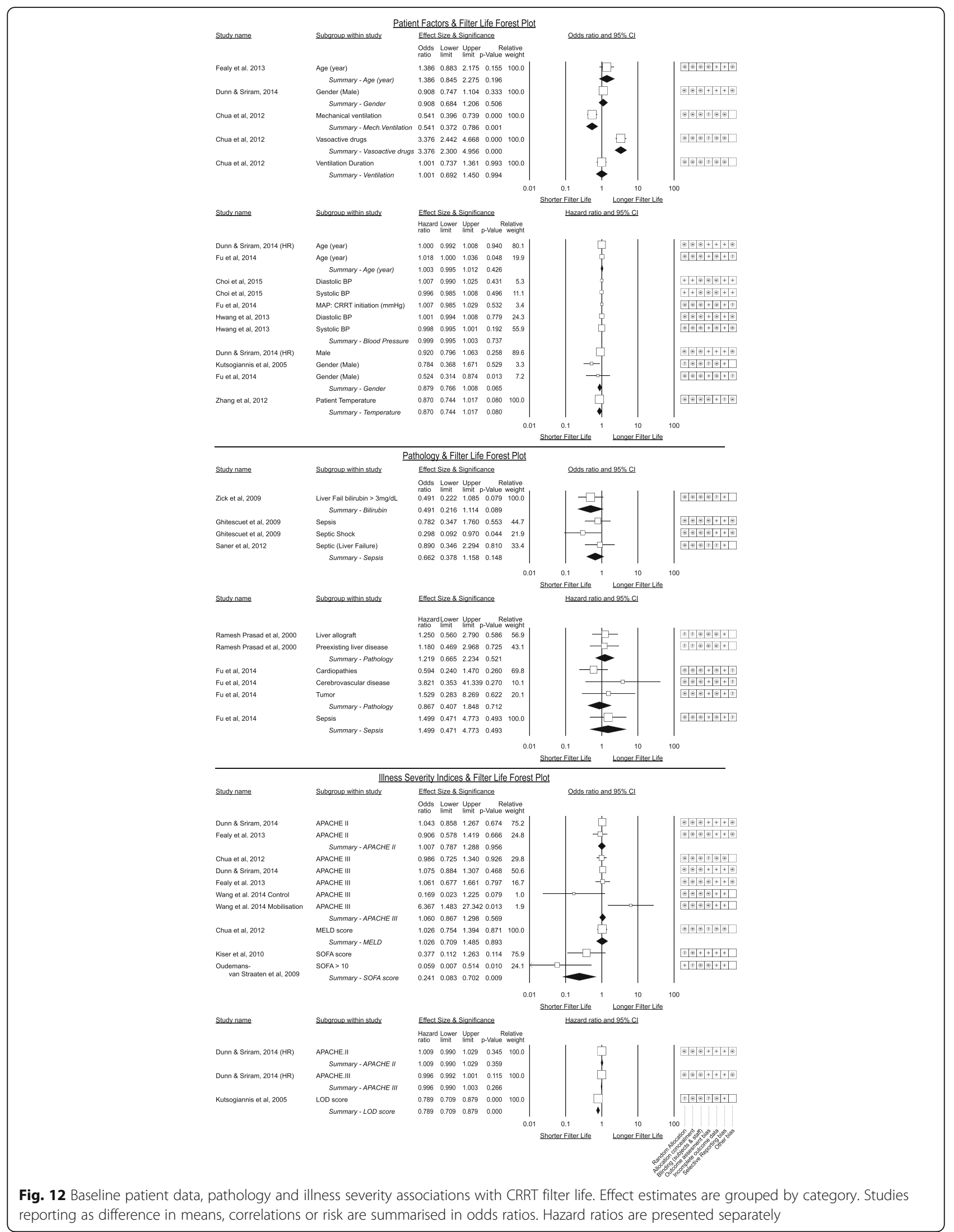




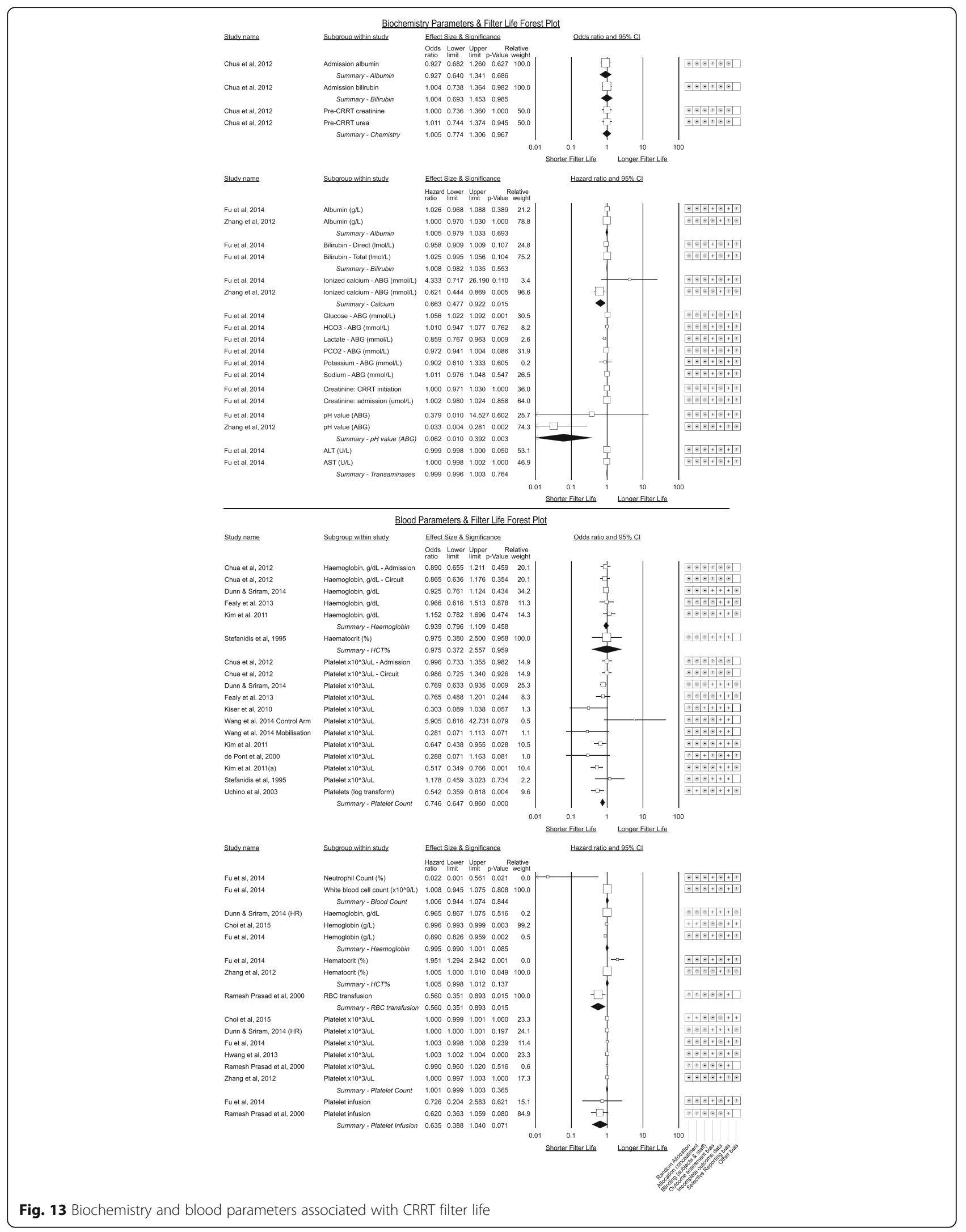




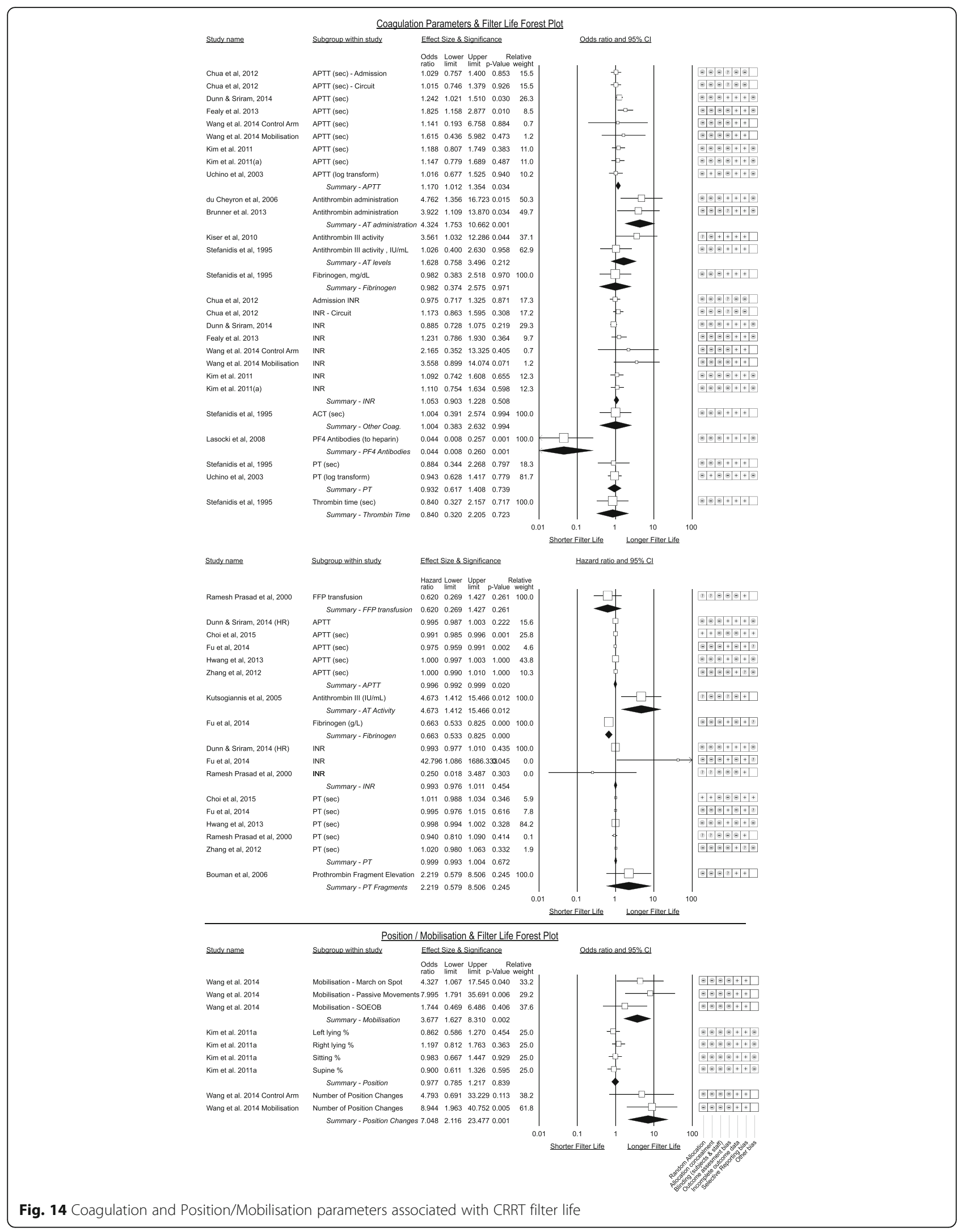


Table 5 Summary of findings table

\begin{tabular}{|c|c|}
\hline Outcomes & Impact \\
\hline
\end{tabular}

Vascular Access interventions to prolong filter life in CRRT

Temporary Vascular Access Site Optimal vascular access site ranked by association with longer filter life is: tunneled semi-permanent, femoral or internal jugular, subclavian site. ${ }^{a}$

Tunneled Semi-permanent Tunneled semi-permanent vascular access devices were Catheters vs Temporary Catheters consistently associated with longer filter life. A significant confounder is that these devices were often larger internal diameter than temporary devices however on the basis of current literature they should be considered in any cases expected to have prolonged CRRT requirement

Side of Vascular Access Catheter

Overall there is insufficient data and possibility of significan confounding by order of catheter choice such that optimal side of vascular access cannot be determined

Catheter length at thoracic vein sites

Favours longer catheter length with atrial placement when thoracic veins utilised. Single study only however unlike most filter life studies this was randomized. No increased in arrhythmias with longer catheter length however underpowered to detect complications.

Catheter lumen size

Only one small study directly measured filter life with catheter size however indirect measures (increased renal dose) in RENAL study supports catheter size as important. Possible benefit from tunneled access may be due to catheter size

Number of vascular access related Number of vascular access alarms is likely a significant alarms contributor to poor filter life however data is limited

Access Catheter Type

No significant difference between brands of catheters though trend existed. Tunneled catheters were superior to temporary catheters

Circuit Management Interventions to Prolong Filter Life in CRRT

Haemofilter Membrane
Characteristics

CRRT Modality

Pre vs Post Dilution in $\mathrm{CWH}$

Blood Flow Rate

Saline Flushes to Blood Path

Education and Alarm Management
Hollow fibre membranes appear superior to flat plate membranes. It is unclear if an advantage exists for polyacrylonitrile membranes compared to polysulfone or cellulose membranes in regards to filter life. Membrane area was not associated with increased filter life in a single study.

$\mathrm{CWH}$ is associated with worse filter life in published studies

One small RCT favoured pre-dilution. Overall affect from all studies trended toward pre-dilution but did not reach significance.

Majority of trials suggest a higher blood flow rate increases filter life however it is unclear over what range this applies. Studies directly comparing low and high blood flow are required.

There is no evidence to support intermittent saline flushing of the circuit to prolong filter life

Limited evidence suggests focused training to recognise and respond to filter warnings prolongs filter life
(9 observational studies) VERY LOW a,b,c

(4 observational studies) LOW $b, c$

(3 observational studies) LOW

(1 RCT) MODERATE $^{d}$

(3 observational studies) VERY LOW ${ }^{\mathrm{a}, \mathrm{c}, \mathrm{e}}$

(1 observational study) VERY LOW 9

(4 observational studies) LOW $^{b, e, g}$

(8 observational studies) VERY LOW ${ }^{\mathrm{h}}$

(7 observational studies) LOW $^{i}$

(4 observational studies) VERY LOW

(9 observational studies) VERY LOW

(4 observational studies) VERY LOW

(4 observational studies) VERY LOW

VERY LOW ${ }^{b j, j, c}$

Factors with a positive association Increasing age (NS), Presence of vaso-active drugs (NS) ${ }^{f}$, with filter life lower pH (sig), Higher APTT (sig), Higher ATIII level (NS), Correction of ATIII deficiency (sig), Mobilization (sig) ${ }^{f}$, Number of position changes (sig) ${ }^{f}$ 
Table 5 Summary of findings table (Continued)

Factors with a negative association with filter life

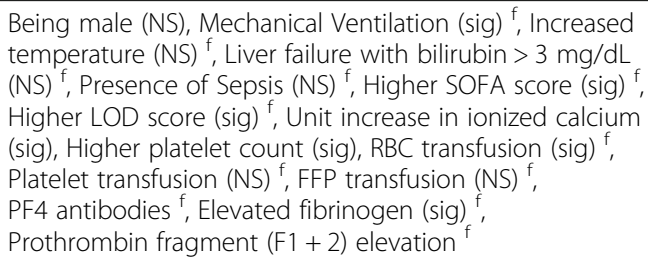

GRADE Working Group grades of evidence:

High quality: We are very confident that the true effect lies close to that of the estimate of the effect

Moderate quality: We are moderately confident in the effect estimate: The true effect is likely to be close to the estimate of the effect, but there is a possibility that it is substantially different

Low quality: Our confidence in the effect estimate is limited: The true effect may be substantially different from the estimate of the effect Very low quality: We have very little confidence in the effect estimate: The true effect is likely to be substantially different from the estimate of effect

${ }^{a}$ Significant heterogeneity exists and potential for confounders

${ }^{\mathrm{b}}$ Timing of catheters during admission has not been studied. Other factors such as choice of catheter length, insertion technique/operator experience at different sites and catheter size at different sites may bias results

cHeterogeneity across small observational studies

¿Unblinded (however unavoidable) however unlikely to affect results

eOne direct study, strong suggestion that the benefit of tunneled access could be due to catheter size, large RCT post hoc suggests larger size important

fSingle study, low numbers

${ }^{9}$ Before - after studies with significant risk of other practice changes

${ }^{\mathrm{h}}$ Mixed composite of varying quality and study designs with no direct comparison between groups

iSome studies used composite interventions

'Mostly small observational studies with high risk of bias

that subclavian placement should remain the last choice of site.

Infection rates rise most per catheter day for femoral and jugular sites $[77,79]$ thus we suggest that in patients where CRRT is anticipated to extend beyond 7-10 days a tunnelled semi-permanent device via an internal jugular vein could offer the optimal filter life with minimal infection risk.

Femoral sites may also predispose to an increased risk of deep venous thrombosis though this finding is not universal [81, 82]. The clinical risk of lower limb deep vein thrombosis however is greater than upper limb thrombosis.

Variations in catheter design have been extensively described [1-3, 83]. This meta-analysis does suggest a trend toward some catheter designs being superior however to date studies have been small and at high risk of confounding and bias. Future catheter technology ideally should be subject to more rigorous comparisons.

\section{Circuit factors}

The evidence base for justifying decisions regarding optimal CRRT mode of therapy is weak though CVVHD-F does appear to offer superior filter life to CVVH consistently in all studies. Even this conclusion is complicated by multiple interacting factors including anticoagulation choice, blood flow determination, nursing expertise and vascular access.

The literature remains unclear in regards to optimal choice of haemofilter membrane despite several evolutions of this technology. Recent advances such as heparin bonded surfaces to minimise cytokine activation and activation of clotting do not have a strong evidence base to demonstrate superiority in regards to filter life though as individual study authors point out, any effect may be synergistic with choice of anticoagulation [43]. Advantages of improved biocompatibility may not be evident in filter life but in overall patient tolerance with an endotoxic shock model in dogs suggesting improved haemodynamic function with polyacrylonitrile over polysulfone [84] membranes.

Factors such as utilising larger surface area haemofilters to gain longer filter life require more data to demonstrate if any benefit exists from either a filter life, cost or performance perspective. Larger area membranes increase clearance of solutes and for the same flow rates facilitate more rapid restoration of physiologic electrolytes however patient outcome studies are required to determine if this translates to clinical improvement. Conversely there seems little evidence to support saline flushes of circuits used with or without anticoagulation and theoretically this practice may expose the blood path to increased risk of microbial contamination.

There is scope to further investigate optimal blood flow rate in larger datasets or randomised studies while controlling for consistency in anticoagulation and vascular access as this is a simple parameter to adjust that affects both membrane performance and, our results suggest, filter life. Such studies should also address alarm frequency as blood flow increases as we hypothesise that any benefit would reach a maximum after which the frequency of access pressure alarms would increase.

Only two studies were found focussing on change management and strategies for staff managing CRRT 
despite this therapy consuming significant human resources with frequent bag changes, alarms and poor filter life predominating. Approach to alarms, catheter positioning, choice of blood flow and general trouble shooting likely varies widely yet has been only touched upon sparingly in filter life studies.

\section{Patient factors}

Patient factors associated with filter life are summarised in Table 5 and in general result from a weak evidence base. Many factors that positively influenced filter life are biologically feasible though the trend in a single study of mobilisation improving filter life requires replication.

No studies reported subgroup analysis where indices of body mass index (BMI) were assessed for an effect on filter life. Similarly, no studies described the effects of patient sedation and only one study described an interaction with ventilation despite both factors appearing at the bedside to influence CRRT interruptions.

More work is required in the group with coagulation disorders such as decreased anti-thrombin (heparin resistance), PF4-heparin antibodies and elevated fibrinogen. 'Clotty' patients have long been recognised as detrimental to CRRT and though the recent expansion of alternatives to heparin (particularly citrate anticoagulation) have broadened therapeutic options these patients still present a challenge frequently cycling through different strategies empirically or unique un-trialled interventions such as plasma exchange for frequent circuit failure with hyperfibrinogenemia [85].

\section{Limitations}

Future data may clarify if effects such as increasing temperature being negatively associated with filter life remain significant. By not randomising for these outcomes there is a significant risk of unquantified bias explaining the effect or multicollinearity where the observed effect is actually tracking another measured or latent variable $[22,25,86,87]$. For example, the trend toward shorter filter life with elevated temperature may track with the trend for sepsis and poor filter life. Given that CRRT typically suppresses body temperature in all but the hottest patients this is particularly possible.

Risk of type I error also exists with an example being APTT where the effect size for a unit increase in APTT though statistically significant appears small (and in some studies in an unexpected direction). Higher APTT values would biologically be expected to prolong extracorporeal circuit life however it is an important variable that practitioners of CRRT control or target toward fixed values thus it is not a 'free' variable in the regression [86].

The overall quality of evidence from studies is low with few randomised studies and none of significant size.
For many variables, effect sizes were extracted from subanalysis utilising either multiple regression or Cox proportional hazards models and this poses limitations on interpretation. For isolated statistically significant findings from single sub-analysis there is a risk of the effect resulting from pure chance i.e. a type II error - however if an association is biologically plausible and is consistent across several studies then it is a strength of metaanalyses that it won't be dismissed.

This systematic review highlighted the dearth of randomised studies to guide practice and the overall low quality of most studies. A significant risk of publication bias exists given the 102 anti-coagulant comparison studies in CRRT each of which would have had vascular access, circuit and patient properties that was only presented in sub-analyses of 10 studies - we deemed it impractical to pursue this volume of unpublished data. Given the limitations above the findings of this metaanalysis should be considered as a summary of published data and remain hypothesis generating.

The diversity of current practice and limited numbers of large controlled trials significantly hamper interpretation of findings. However, many effects that reached significance are largely consistent with clinical experience and highlight where clinical decision making and future studies should consider the existing data such as around timing of transfusions, involvement of mobilisation and coagulation strategies in septic patients.

This review is useful in highlighting the weak underpinnings of current clinical practice in this area. Filter life is an objective measurement that can readily be followed within a unit as a quality control and understanding factors that influence variability will aide improvements of this index.

This review also highlighted some omissions in the literature; though studies have looked at operator experience and ultrasound guided insertion in relation to vascular access complications [88-90], filter life has not been assessed as an outcome of ultrasound guided catheter placement. Studies of alarm frequency by catheter site and interactions with patient position need further investigation. No studies reported on an interaction between catheter site and body habitus in regards to filter life - we postulate that patients with centripetal obesity may be more likely to receive jugular catheters and this may interact with filter life. No studies looked at catheter care and locking in relation to filter life.

\section{Conclusion}

Despite the improvements in device technology and usability, filter life remains highly variable across published literature. This is somewhat unsurprising given the myriad of interacting patient, vascular access site and type and circuit factors. Perhaps more surprising is 
the absence of strong guiding evidence outside of anticoagulation strategies after over 20 years of therapy delivery. Significant ongoing data collection is required to elucidate the optimal technological and management strategies to enhance current delivery of care to provide optimal performance with minimal disruption at the least cost.

\section{Abbreviations \\ AKI: Acute Kidney Injury; CRRT: Continuous Renal Replacement Therapy; CWH: Continuous Veno-venous Haemofiltration: CWHD: Continuous Veno-venous Haemodialysis; CWHD-F: Continuous Veno-venous Haemodiafiltration; Qb: Blood flow (ml/min); RCT: Randomised Controlled Trial}

\section{Acknowledgements}

Wendy Dunn, Clinical Nurse Specialist, Royal Melbourne Hospital, Victoria. Noelene Westerneng and Marie Manshanden, Sir John Ramsay Memorial Library. Launceston General Hospital, Tasmania.

Monash University Library Staff

\section{Funding}

The authors declare no specific funding was allocated to this study.

Institutions provided library resources and research time allotment.

\section{Availability of data and materials}

All study data has been derived from the published literature as described in methods and the presented data will be available from date of publication in spreadsheet format from Monash University Figshare [91]: https://dx.doi.org/10.4225/03/5848bb75cfaf4.

Where individual study authors contacted as part of this review have provided additional data for reanalysis, this data has not been uploaded. Access to this data will be provided if permission from the original authors is obtained.

\section{Authors' contributions}

$M B, O R$ and JM conceived investigation. MB performed background work, design of search strategy, analysis and write up. LW and MB independently selected abstracts, classified full text articles for inclusion and performed data entry and jointly assessed interpretation of findings. OR and JM provided direction on structure, presentation, interpretation and write up of findings. All authors read and approved the final manuscript.

\section{Competing interests}

The authors declare that they have no competing interests.

\section{Consent for publication}

Not applicable.

\section{Ethics approval and consent to participate}

Not applicable. No patients are discussed or were involved in this publication. All data sources are from previously published literature.

\section{Author details}

'School of Public Health and Preventive Medicine, Monash University, Melbourne, VIC, Australia. ${ }^{2}$ The Alfred Intensive Care Unit, Melbourne, VIC Australia. ${ }^{3}$ Launceston General Hospital, Launceston, TAS, Australia.

Received: 10 September 2016 Accepted: 10 January 2017

Published online: 20 February 2017

\section{References}

1. Joannidis M, Oudemans-van Straaten HM. Clinical review: patency of the circuit in continuous renal replacement therapy. Crit Care. 2007;11:218

2. Baldwin I. Factors affecting circuit patency and filter "life". Contrib Nephrol. 2007;156:178-84

3. Davies H, Leslie G. Maintaining the CRRT circuit: non-anticoagulant alternatives. Aust Crit Care. 2006;19:133-8.
4. Davies H, Leslie G. Anticoagulation in CRRT: agents and strategies in Australian ICUs. Aust Crit Care. 2007:20:15-26.

5. Oudemans-van Straaten HM, Kellum JA, Bellomo R. Clinical review: anticoagulation for continuous renal replacement therapy-heparin or citrate? Crit Care. 2011;15:202.

6. Wu M-Y, Hsu Y-H, Bai C-H, Lin Y-F, Wu C-H, Tam K-W. Regional citrate versus heparin anticoagulation for continuous renal replacement therapy: a meta-analysis of randomized controlled trials. Am J Kidney Dis. 2012;59:810-8.

7. Bai M, Zhou M, He L, Ma F, Li Y, Yu Y, et al. Citrate versus heparin anticoagulation for continuous renal replacement therapy: an updated meta-analysis of RCTs. Intensive Care Med. 2015;41:2098-110.

8. Stroup DF, Berlin JA, Morton SC, Olkin I, Williamson GD, Rennie D, et al. Meta-analysis of observational studies in epidemiology: a proposal for reporting. Meta-analysis Of Observational Studies in Epidemiology (MOOSE) group. JAMA. 2000;283:2008-12.

9. Google Translate [Internet]. [cited 2016 Mar 4]. Available from: https:// translate.google.com.au/

10. Borenstein, Michael, Hedges, Larry, Higgins, Julian, Rothstein, Hannah. Comprehensive Meta-Analysis Software (CMA) [Internet]. [cited 2016 Mar 4]. Available from: https://www.meta-analysis.com/.

11. Review Manager (Revman) [Internet]. Copenhagen: The Nordic Cochrane Centre, The Cochrane Collaboration; 2014 [cited 2016 Mar 4]. Available from: http://tech.cochrane.org/revman.

12. Rosenthal $R$, Rubin DB. r-sub(equivalent): a simple effect size indicator. Psychol Methods. 2003;8:492-6.

13. Aloe AM, Becker BJ. An effect size for regression predictors in meta-analysis. J Educ Behav Stat. 2012:37:278-97.

14. Peterson RA, Brown SP. On the use of beta coefficients in meta-analysis. J Appl Psychol. 2005;90:175-81.

15. Liu Z, Rich B, Hanley JA. Recovering the raw data behind a non-parametric survival curve. Syst. Rev. [Internet]. 2014 [cited 2016 Feb 17]:3. Available from: http://www.ncbi.n/m.nih.gov/pmc/articles/PMC4293001/.

16. J Hanley: Data Recovery [Internet]. [cited 2016 Feb 17]. Available from: http://www.med.mcgill.ca/epidemiology/hanley/software/DataRecovery/.

17. Williamson PR, Smith CT, Hutton JL, Marson AG. Aggregate data metaanalysis with time-to-event outcomes. Stat Med. 2002;21:3337-51.

18. Parmar MKB, Torri $V$, Stewart L. Extracting summary statistics to perform meta-analyses of the published literature for survival endpoints. Stat Med. 1998;17:2815-34

19. Mitchell, Mark. Engauge Digitizer [Internet]. 2014 [cited 2016 Feb 17]. Available from: http://digitizer.sourceforge.net/.

20. R. Core Team. R: A Language and Environment for Statistical Computing [Internet]. Vienna, Austria; 2013. Available from: http://www.R-project.org/.

21. Therneau T. A Package for Survival Analysis in S. R package [Internet]. Vienna, Austria; 2015. Available from: http://CRAN.R-project.org/package=survival.

22. Cochrane Handbook for Systematic Reviews of Interventions [Internet]. Version 5.1.0. The Cochrane Collaboration; 2011. Available from: www. cochrane-handbookorg.

23. Dunn WJ, Sriram S. Filter lifespan in critically ill adults receiving continuous renal replacement therapy: the effect of patient and treatment-related variables. Crit Care Resusc J Australas Acad Crit Care Med. 2014;16:225-31.

24. Crosswell A, Brain MJ, Roodenburg O. Vascular access site influences circuit life in continuous renal replacement therapy. Crit Care Resusc J Australas Acad Crit Care Med. 2014;16:127-30.

25. Evidence Prime, Inc. GRADEpro GDT: GRADEpro Guideline Development Tool [Internet]. McMaster University; 2015 [cited 2016 Mar 4]. Available from: http://gradepro.org/.

26. Morgan D, Ho K, Murray C, Davies H, Louw J. A randomized trial of catheters of different lengths to achieve right atrium versus superior vena cava placement for continuous renal replacement therapy. Am J Kidney Dis Off J Natl Kidney Found. 2012:60:272-9.

27. Brain MJ, Roodenburg OS, Adams N, McCracken P, Hockings L, Musgrave S, et al. Randomised trial of software algorithm driven regional citrate anticoagulation versus heparin in continuous renal replacement therapy: the Filter Life in Renal Replacement Therapy pilot trial. Crit Care Resusc J Australas Acad Crit Care Med. 2014;16:131-7.

28. Parienti J-J, Mégarbane B, Fischer M-O, Lautrette A, Gazui N, Marin N, et al. Catheter dysfunction and dialysis performance according to vascular access among 736 critically ill adults requiring renal replacement therapy: a randomized controlled study. Crit Care Med. 2010;38:1118-25. 
29. Bellomo R, Mårtensson J, Lo S, Kaukonen K-M, Cass A, Gallagher M, et al. Femoral access and delivery of continuous renal replacement therapy dose. Blood Purif. 2015;41:11-7.

30. Choi J-Y, Kang $\mathrm{Y}-\mathrm{J}$, Jang HM, Jung H-Y, Cho J-H, Park S-H, et al. Nafamostat Mesilate as an anticoagulant during continuous renal replacement therapy in patients with high bleeding risk: a randomized clinical trial. Medicine (Baltimore). 2015;94:e2392.

31. De Pont AC, Oudemans-van Straaten HM, Roozendaal KJ, Zandstra DF. Nadroparin versus dalteparin anticoagulation in high-volume, continuous venovenous hemofiltration: a double-blind, randomized, crossover study. Crit Care Med. 2000;28:421-5.

32. Kiser TH, MacLaren R, Fish DN, Hassell KL, Teitelbaum I. Bivalirudin versus unfractionated heparin for prevention of hemofilter occlusion during continuous renal replacement therapy. Pharmacotherapy. 2010;30:1117-26.

33. Kutsogiannis DJ, Gibney RTN, Stollery D, Gao J. Regional citrate versus systemic heparin anticoagulation for continuous renal replacement in critically ill patients. Kidney Int. 2005;67:2361-7.

34. Oudemans-van Straaten HM, van Schilfgaarde M, Molenaar PJ, Wester JP, Leyte A. Hemostasis during low molecular weight heparin anticoagulation for continuous venovenous hemofiltration: a randomized cross-over trial comparing two hemofiltration rates. Crit Care Lond Engl. 2009;13:R193.

35. Du Cheyron D, Bouchet B, Bruel C, Daubin C, Ramakers M, Charbonneau P. Antithrombin supplementation for anticoagulation during continuous hemofiltration in critically ill patients with septic shock: a case-control study. Crit Care Lond Engl. 2006;10:R45.

36. Wang YT, Haines TP, Ritchie P, Walker C, Ansell TA, Ryan DT, et al. Early mobilization on continuous renal replacement therapy is safe and may improve filter life. Crit Care Lond Engl. 2014;18:R161.

37. Kim IB, Fealy N, Baldwin I, Bellomo R. Insertion side, body position and circuit life during continuous renal replacement therapy with femoral vein access. Blood Purif. 2011;31:42-6.

38. Mottes T, Owens T, Niedner M, Juno J, Shanley TP, Heung M. Improving delivery of continuous renal replacement therapy: impact of a simulationbased educational intervention. Pediatr Crit Care Med J Soc Crit Care Med World Fed Pediatr Intensive Crit Care Soc. 2013;14:747-54

39. Zhang L, Tanaka A, Zhu G, Baldwin I, Eastwood GM, Bellomo R. Patterns and mechanisms of artificial kidney failure during continuous renal replacement therapy. Blood Purif. 2015;41:254-63.

40. Baldwin I, Bridge N, Heland M, Buckmaster J, Davies A, Hart G, et al. The effect of filter configuration on extracorporeal circuit life during continuous veno-venous haemofiltration. Aust Crit Care. 1996;9:22.

41. Fu X, Liang X, Song L, Huang H, Wang J, Chen Y, et al. Building and validation of a prognostic model for predicting extracorporeal circuit clotting in patients with continuous renal replacement therapy. Int Urol Nephrol. 2014;46:801-7

42. Pichaiwong W, Leelahavanichkul A, Eiam-ong S. Efficacy of cellulose triacetate dialyzer and polysulfone synthetic hemofilter for continuous venovenous hemofiltration in acute renal failure. J Med Assoc Thail Chotmaihet Thangphaet. 2006;89 Suppl 2:S65-72.

43. Schetz M, Van Cromphaut S, Dubois J, Van den Berghe G. Does the surface-treated AN69 membrane prolong filter survival in CRRT without anticoagulation? Intensive Care Med. 2012;38:1818-25.

44. Yin Y, Zhao C, Hu Z, Wei S, Huo Y. The effect of AN69 ST membrane on filter lifetime in continuous renal replacement therapy without anticoagulation in patients with high risk of bleeding. Zhonghua Wei Zhong Bing Ji Jiu Yi Xue. 2015;27:343-8.

45. Bonassin Tempesta F, Rudiger A, Previsdomini M, Maggiorini M. Platelet consumption and filter clotting using two different membrane sizes during continuous venovenous haemodiafiltration in the intensive care unit. Crit Care Res Pract. 2014;2014:203637.

46. Davies HT, Leslie G, Pereira SM, Webb SA. R A randomized comparative crossover study to assess the affect on circuit life of varying pre-dilution volume associated with CWH and CWHDF. Int J Artif Organs. 2008;31:221-7.

47. Ricci Z, Ronco C, Bachetoni A, D’amico G, Rossi S, Alessandri E, et al. Solute removal during continuous renal replacement therapy in critically ill patients: convection versus diffusion. Crit Care Lond Engl. 2006;10:R67.

48. De Pont A-CJM, Bouman CSC, Bakhtiari K, Schaap MCL, Nieuwland R, Sturk $A$, et al. Predilution versus postdilution during continuous venovenous hemofiltration: a comparison of circuit thrombogenesis. ASAIO J Am Soc Artif Intern Organs 1992. 2006;52:416-22.
49. Van der Voort PHJ, Gerritsen RT, Kuiper MA, Egbers PHM, Kingma WP, Boerma EC. Filter run time in CWH: pre- versus post-dilution and nadroparin versus regional heparin-protamine anticoagulation. Blood Purif. 2005:23:175-80.

50. Chua H-R, Baldwin I, Bailey M, Subramaniam A, Bellomo R. Circuit lifespan during continuous renal replacement therapy for combined liver and kidney failure. J Crit Care. 2012;27:744.e7-744.e15.

51. RENAL Study Investigators (last). Intensity of Continuous Renal-Replacement Therapy in Critically III Patients. N Engl J Med. 2009;361:1627-38.

52. Palevsky PM, Zhang JH, O'connor TZ, Chertow GM, Crowley ST, Choudhury D, et al. ATN Study : Intensity of renal support in critically ill patients with acute kidney injury. N Engl J Med. 2008;359:7-20.

53. Ramesh Prasad GV, Palevsky PM, Burr R, Lesko JM, Gupta B, Greenberg A. Factors affecting system clotting in continuous renal replacement therapy: results of a randomized, controlled trial. Clin Nephrol. 2000;53:55-60.

54. Eastwood GM, Peck L, Young H, Bailey M, Reade MC, Baldwin I, et al. Haemodynamic impact of a slower pump speed at start of continuous renal replacement therapy in critically III adults with acute kidney injury: a prospective before-and-after study. Blood Purif. 2012;33:52-8.

55. Baldwin I, Bridge N, Heland M, Buckmaster J, Davies A, Hart G, et al. The effect of heparin administration site on extracorporeal circuit life during continuous veno-venous haemofiltration. Aust Crit Care. 1996;9:29.

56. Leslie GD, Jacobs IG, Clarke GM. Proximally delivered dilute heparin does not improve circuit life in continuous venovenous haemodiafiltration. Intensive Care Med. 1996;22:1261-4

57. Baldwin I, Fealy N, Carty P, Boyle M, Kim I, Bellomo R. Bubble chamber clotting during continuous renal replacement therapy: vertical versus horizontal blood flow entry. Blood Purif. 2012;34:213-8.

58. Reeves JH, Seal PF, Voss AL, O'Connor C. Albumin priming does not prolong hemofilter life. ASAIO J Am Soc Artif Intern Organs 1992. 1997;43:193-6.

59. Rickard CM, Couchman BA, Hughes M, McGrail MR. Preventing hypothermia during continuous veno-venous haemodiafiltration: a randomized controlled trial. J Adv Nurs. 2004:47:393-400.

60. Hwang SD, Hyun YK, Moon SJ, Lee SC, Yoon SY. Nafamostat mesilate for anticoagulation in continuous renal replacement therapy. Int J Artif Organs. 2013;36:208-16

61. Nagarik AP, Soni SS, Adikey GK, Raman A. Comparative study of anticoagulation versus saline flushes in continuous renal replacement therapy. Saudi J Kidney Dis Transplant Off Publ Saudi Cent Organ Transplant Saudi Arab. 2010;21:478-83.

62. Panphanpho S, Naowapanich S, Ratanarat R. Use of saline flush to prevent filter clotting in continuous renal replacement therapy without anticoagulant. J Med Assoc Thail Chotmaihet Thangphaet. 2011;94 Suppl 1:S105-10.

63. Kim IB, Fealy N, Baldwin I, Bellomo R. Premature circuit clotting due to likely mechanical failure during continuous renal replacement therapy. Blood Purif. 2010:30:79-83.

64. Zhang Z, Ni H, Lu B. Variables associated with circuit life span in critically ill patients undergoing continuous renal replacement therapy: a prospective observational study. ASAIO J Am Soc Artif Intern Organs 1992. 2012:58:46-50.

65. Ghitescu I, Copotoiu SM, Toma RS, Ghitescu VT, Copotoiu R. Mean filter life span in continuous veno-venous hemofiltration for septic patients. Jurnalul Roman Anestezie Ter Intensiv J Anaesth Intensive Care. 2009:16:17-22

66. Agarwal B, Shaw S, Shankar Hari M, Burroughs AK, Davenport A. Continuous renal replacement therapy (CRRT) in patients with liver disease: is circuit life different? J Hepatol. 2009;51:504-9.

67. Brunner R, Leiss W, Madl C, Druml W, Holzinger U. Single-dose application of antithrombin as a potential alternative anticoagulant during continuous renal replacement therapy in critically ill patients with advanced liver cirrhosis: a retrospective data analysis. Anesth Analg. 2013;116:527-32

68. Zick G, Wilms C, Renders L, Schulz J, Frerichs A, Frerichs I, et al. Continuous renal replacement therapy with regional citrate anticoagulation in patients with liver failure - A prospective observational study. [German]. Anasthesiologie Intensivmed. 2009;50:580-91.

69. Goonasekera CD, Wang J, Bunchman TE, Deep A. Factors affecting circuit life during continuous renal replacement therapy in children with liver failure. Ther Apher Dial Off Peer-Rev J Int Soc Apher Jpn Soc Apher Jpn Soc Dial Ther. 2015;19:16-22 
70. Slowinski T, Morgera S, Joannidis M, Henneberg T, Stocker R, Helset E, et al. Safety and efficacy of regional citrate anticoagulation in continuous venovenous hemodialysis in the presence of liver failure: the Liver Citrate Anticoagulation Threshold (L-CAT) observational study. Crit Care Lond Engl. 2015;19:349.

71. Balogun RA, Turgut F, Caldwell S, Abdel-Rahman EM. Regional citrate anticoagulation in critically ill patients with liver and kidney failure. J Nephrol. 2012;25:113-9.

72. Bouman CSC, de Pont A-CJM, Meijers JCM, Bakhtiari K, Roem D, Zeerleder S, et al. The effects of continuous venovenous hemofiltration on coagulation activation. Crit Care Lond Engl. 2006;10:R150.

73. Stefanidis I, Hägel J, Maurin N. Influence of coagulation parameters on filter running time during continuous venovenous hemofiltration. Contrib Nephrol. 1995;116:145-9.

74. Lasocki S, Piednoir P, Ajzenberg N, Geffroy A, Benbara A, Montravers $P$. Anti-PF4/heparin antibodies associated with repeated hemofiltration-filter clotting: a retrospective study. Crit Care Lond Engl. 2008;12:R84.

75. Toonstra AL, Zanni JM, Sperati CJ, Nelliot A, Mantheiy E, Skinner EH, et al. Feasibility and safety of physical therapy during continuous renal replacement therapy in the intensive care unit. Ann Am Thorac Soc 2016;699-704

76. Hryszko T, Brzosko S, Mazerska M, Malyszko J, Mysliwiec M. Risk factors of nontunneled noncuffed hemodialysis catheter malfunction. Nephron Clin Pract. 2004;96:C43-7.

77. Oliver MJ, Callery SM, Thorpe KE, Schwab SJ, Churchill DN. Risk of bacteremia from temporary hemodialysis catheters by site of insertion and duration of use: a prospective study. Kidney Int 2000;58:2543-5

78. Parienti J-J, Mongardon N, Mégarbane B, Mira J-P, Kalfon P, Gros A, et al. Intravascular complications of central venous catheterization by insertion site. N Engl J Med. 2015;373:1220-9.

79. Kairaitis L. Outcome and complications of temporary haemodialysis catheters. Nephrol Dial Transplant. 1999;14:1710-4.

80. Cimochowski GE, Worley E, Rutherford WE, Sartain J, Blondin J, Harter H. Superiority of the internal jugular over the subclavian access for temporary dialysis. Nephron. 1990;54:154-61.

81. Trottier SJ, Veremakis C, O'Brien J, Auer Al. Femoral deep vein thrombosis associated with central venous catheterization: results from a prospective, randomized trial. Crit Care Med. 1995:23:52-9.

82. Lipcsey M, Chua H-R, Schneider AG, Robbins R, Bellomo R. Clinically manifest thromboembolic complications of femoral vein catheterization for continuous renal replacement therapy. J Crit Care. 2014;29:18-23.

83. Canaud B, Leray-Moragues H, Leblanc M, Klouche K, Vela C, Béraud JJ. Temporary vascular access for extracorporeal renal replacement therapies in acute renal failure patients. Kidney Int Suppl. 1998;66:S142-50.

84. Rogiers $P$, Zhang H, Pauwels D, Vincent J-L. Comparison of polyacrylonitrile (AN69) and polysulphone membrane during hemofiltration in canine endotoxic shock: Crit. Care Med. 2003:31:1219-25.

85. Fülöp $T$, Cosmin A, Juncos LA. Recurring extracorporeal circuit clotting during continuous renal replacement therapy resolved after single-session therapeutic plasma exchange. J Clin Apheresis. 2011;26:214-5.

86. Box GEP. Use and abuse of regression. Technometrics. 1966;8:625-9.

87. Ramsay JO, Silverman BW. Applied functional data analysis: methods and case studies. Springer New York; 2002

88. Geddes CC, Walbaum D, Fox JG, Mactier RA. Insertion of internal jugular temporary hemodialysis cannulae by direct ultrasound guidance-a prospective comparison of experienced and inexperienced operators. Clin Nephrol. 1998:50:320-5.

89. Headley CM, Thompson CL, Carter M, Khan A, Wall BM. The role of real-time ultrasound and physical examination measurements in placement of cuffed-tunneled hemodialysis catheters. Nephrol Nurs J. 2004:31:407+

90. Karakitsos D, Saranteas T, Patrianakos AP, Labropoulos N, Karabinis A. Ultrasound-guided" Low Approach" femoral vein catheterization in critical care patients results in high incidence of deep vein thrombosis. Anesthesiology. 2007;107:181-2.

91. Brain MJ. Non Anti-Coagulant Factors Associated with Filter Life in Continuous Renal Replacement Therapy (CRRT): A systematic review and meta-analysis. Study Data [Internet]. [cited 2016 Dec 8]. Available from: https://dx.doi.org/10.4225/03/5848bb75cfaf4.
92. Kim I, Fealy N, Baldwin I, Bellomo R. A comparison of the Niagara ${ }^{\mathrm{TM}}$ and Dolphin $^{\oplus}$ catheters for continuous renal replacement therapy. Int J Artif Organs. 2011;34:1061-6.

93. Fealy N, Kim I, Baldwin I, Schneider A, Bellomo R. A comparison of the Niagara and Medcomp catheters for continuous renal replacement therapy. Ren Fail. 2013;35:308-13.

94. Sponholz C, Bayer O, Kabisch B, Wurm K, Ebert K, Bauer M, et al. Anticoagulation strategies in venovenous hemodialysis in critically ill patients: a five-year evaluation in a surgical intensive care unit. ScientificWorldJournal. 2014;2014:808320.

95. Martin PY, Chevrolet JC, Suter P, Favre H. Anticoagulation in patients treated by continuous venovenous hemofiltration: a retrospective study. Am J Kidney Dis Off J Natl Kidney Found. 1994;24:806-12.

96. Uchino S, Fealy N, Baldwin I, Morimatsu H, Bellomo R. Pre-dilution vs. post-dilution during continuous veno-venous hemofiltration: impact on filter life and azotemic control. Nephron Clin Pract. 2003;94:C94-8.

97. Egi M, Naka T, Bellomo R, Cole L, French C, Trethewy C, et al. A comparison of two citrate anticoagulation regimens for continuous veno-venous hemofiltration. Int J Artif Organs. 2005;28:1211-8.

98. Nurmohamed SA, Jallah BP, Vervloet MG, Beishuizen A, Groeneveld ABJ. Predilution versus postdilution continuous venovenous hemofiltration: no effect on filter life and azotemic control in critically ill patients on heparin. ASAIO J Am Soc Artif Intern Organs 1992. 2011;57:48-52.

99. Morabito S, Pistolesi V, Tritapepe L, Vitaliano E, Zeppilli L, Polistena F, et al. Continuous venovenous hemodiafiltration with a low citrate dose regional anticoagulation protocol and a phosphate-containing solution: effects on acid-base status and phosphate supplementation needs. BMC Nephrol. 2013;14:232.

100. Page M, Rimmelé T, Prothet J, Christin F, Crozon J, Ber C-E. Impact of a program designed to improve continuous renal replacement therapy stability. Ann Fr Anesthèsie Rèanimation. 2014;33:626-30.

101. Ede J, Dale A. Has the use of CWHDF when compared to CWH during CRRT affected the failed circuit life within a major teaching hospital: a service evaluation. Nurs Crit Care. 2016;22:52-7.

102. Saner FH, Treckmann JW, Geis A, Lösch C, Witzke O, Canbay A, et al. Efficacy and safety of regional citrate anticoagulation in liver transplant patients requiring post-operative renal replacement therapy. Nephrol Dial Transplant Off Publ Eur Dial Transpl Assoc - Eur Ren Assoc. 2012;27:1651-7.

103. Morabito S, Pistolesi V, Tritapepe L, Vitaliano E, Zeppilli L, Polistena F, et al. Continuous veno-venous hemofiltration using a phosphate-containing replacement fluid in the setting of regional citrate anticoagulation. Int J Artif Organs. 2013;36:845-52

\section{Submit your next manuscript to BioMed Central and we will help you at every step:}

- We accept pre-submission inquiries

- Our selector tool helps you to find the most relevant journal

- We provide round the clock customer support

- Convenient online submission

- Thorough peer review

- Inclusion in PubMed and all major indexing services

- Maximum visibility for your research

Submit your manuscript at www.biomedcentral.com/submit 